\title{
Exosomes in the ascites of ovarian cancer patients: Origin and effects on anti-tumor immunity
}

\author{
PENG PENG $^{1}$, YOU YAN ${ }^{2}$ and SHEN KENG $^{1}$ \\ Departments of ${ }^{1}$ Obstetrics and Gynecology, and ${ }^{2}$ Pathology, \\ Peking Union Medical College Hospital, Beijing 100730, P.R. China
}

Received August 19, 2010; Accepted November 2, 2010

DOI: $10.3892 /$ or.2010.1119

\begin{abstract}
This study was performed to identify the origin of the ascites-derived exosomes from patients with ovarian cancer and to observe the effect of exosomes on anti-tumor immunity. Exosomes were isolated from the ascites of patients with ovarian epithelial cancer by ultracentrifugation plus density gradient centrifugation. The origin of exosomes was identified by immunoelectronmicroscopy (IEM). The growth curve of the tumor cell line SKOV3 cultured with or without exosomes was analyzed. The apoptosis of autogeneic tumor cells (ATCs) and SKOV3 cells affected by exosomes was measured by flow cytometry (FCM) and light phase contrast microscopy. The cytotoxic effect of the peripheral blood mononuclear cells (PBMCs) stimulated by exosomes and/or dendritic cells (DCs) on ovarian cancer cells was measured using a CCK- 8 assay. The levels of IFN- $\gamma$ released by PBMCs stimulated by exosomes and/or DCs were measured by ELISA. The apoptosis of PBMCs and DCs affected by exosomes was measured by FCM and light microscopy. Whether the mature process of DCs was affected by exosomes was studied by FCM. The ratio of $\mathrm{CD}^{+} \mathrm{T}$ cell and $\mathrm{CD}^{+} \mathrm{T}$ cell were measured by FCM. FasL and TRAIL molecules on exosomes were detected by Western blot analysis. The human FasL antagonistic antibody was used to block the apoptosis of DCs and PBMCs induced by exosomes. The receptors of TRAIL DR4 and DR5 on PBMCs and DCs
\end{abstract}

Correspondence to: Dr Shen Keng, Department of Obstetrics and Gynecology, Peking Union Medical College Hospital, Beijing 100730, P.R.China

E-mail: shenkeng@vip.sina.com

Abbreviations: IEM, immunoelectronmicroscopy; ATCs, autogeneic tumor cells; FCM, flow cytometry; PBMCs, peripheral blood mononuclear cells; DCs, dendritic cells; APC, antigen presenting cell; PBS, phosphate-buffered solution; TEM, transmission electron microscope; OD, optical density; ATCs, autogeneic tumor cells; FCM, flow cytometry; TC, target cells; EC, effector cells; HSCs, hematopoietic stem cells; GM-CSF, granulocytomacrophage colony stimulating factor

Key words: exosome, ovarian carcinoma, cytotoxicity, apoptosis were detected by FCM. In 41 patients examined, we isolated exosomes from the ascites of 35 patients. We detected TCR, CD20, HLA-DR, B7-2, HER2/neu, CA125 and Histone $\mathrm{H}_{2} \mathrm{~A}$ on exosomes. We found that exosomes might impair the cytotoxic activity of PBMCs when DCs are present. We found that exosomes had no effect on the growth and apoptosis of SKOV3 cells. However, exosomes may induce apoptosis of precursors, mature DCs and PBMCs. We found that FasL and TRAIL were present in the exosome suspension and addition of an anti-FasL antibody may decrease the percentage of apoptosis of DCs and PBMCs. We conclude that exosomes exist in ascites of $85.4 \%$ of patients with ovarian cancer. Moreover, these exosomes may be of multi-origin. Exosomes had no effect on the growth and apoptosis of tumor cells but impaired the cytotoxic activity of PBMCs in the presence of DCs. Exosomes also may induce apoptosis of the precursors of DCs, DCs and PBMCs. FasL and TRAIL on exosomes may partly account for the apoptosis of cells of the immune system.

\section{Introduction}

Ovarian cancer is the third leading malignant gynecological tumor but its mortality is the highest. There are still many puzzles of ovarian cancer, including the relationship between the tumor and the host immune system, and the mechanisms of the development, invasion and metastasis of the tumor. Exosomes are a kind of microvesicles released by many types of cells such as tumor cell (1-4), antigen presenting cells (APC) $(5,6)$ and epithelial cells $(7,8)$. Recent research revealed that exosomes purified from the ascites of patient with ovarian cancer contain some immunological-effect molecules (9). Some studies showed these ascites-derived exosomes may stimulate the specific host anti-tumor immunity (9) but other studies showed exosomes may depress the host anti-tumor immunity $(10,11)$. In order to explore the origin of the ascites-derived exosomes, and how exosomes play a role in the specific anti-tumor immunological function, this study was performed.

\section{Materials and methods}

Purification and identification of exosomes. Ascites-derived exosomes of ovarian cancer patients were purified by the method of Andre et al (9). Briefly, ascites samples were centrifuged at $300 \mathrm{~g}$ to discard floating cells. Supernatants 
were removed and centrifuged successively at $800 \mathrm{~g}$ for $30 \mathrm{~min}$, $10,000 \mathrm{~g}$ for $30 \mathrm{~min}$, and $100,000 \mathrm{~g}$ for $1 \mathrm{~h}$. After the last centrifugation step, exosomes contained in the $30 \%$ sucrose/ D2O cushion were resuspended in phosphate-buffered solution (PBS), and concentrated in a last step of $1 \mathrm{~h}$ ultracentrifugation at $100,000 \mathrm{~g}$. We resuspended the pellets of exosomes in PBS and stored the solution at $-80^{\circ} \mathrm{C}$.

Exosomes were identified by transmission electron microscope (TEM) and Western blot analysis with polyclonal antibodies to MHC-I (Santa Cruz Biotechnology, Santa Cruz, USA), HSP70 (Stressgen, Canada) and CD81 (Santa Biotechnology) (12).

Detection of the exosomes expressing antigens. The exosome expressing antigens were detected by immunoelectron microscope (IEM) and Western blot analysis with 12\% SDS-PAGE and polyclonal antibodies to Neu (Santa Cruz Biotechnology), HLA-DR (Santa Cruz Biotechnology), B7-2 (Santa Cruz Biotechnology), TCR- $\alpha$ (Santa Cruz Biotechnology), CD20 (Neo Markers, USA) and Histone $\mathrm{H}_{2} \mathrm{~A}$ (Cell Signaling, USA).

The effect of the ascites-derived exosomes on the growth and apoptosis of ovarian cancer cell. We added different volumes of exosomes into the same number of the ovarian cancer cell line SKOV3 cells and tested the optical density (OD) which presented the number of the cells on different time point within $72 \mathrm{~h}$ by CCK-8 kit (Dojindo, Japan). We cultured every $6 \times 10^{5}$ autogeneic tumor cells (ATCs) or SKOV3 cells with exosomes derived from $200 \mathrm{ml}$ ascites for $48 \mathrm{~h}$ and we measured the percentages of early-stage apoptosis, advanced-stage apoptosis and necrosis of these two types of cells. The apoptosis of ATCs and SKOV3 cells co-cultured with exosomes or not was analyzed by flow cytometry (FCM, Coulter Co., USA) using Annexin V-PI staining kit (Biolife, China) and light phase contrast microscope (Nikon, Japan).

The in vitro anti-ovarian cancer effect of the PBMCs stimulated by ascites-derived exosomes

Cell culture and preparation. Tumor cells in the ascites were isolated by centrifugalization at $300 \mathrm{~g}$ for $20 \mathrm{~min}$ and cultured in $5 \% \mathrm{CO}_{2}$ and RPMI-1640 (Gibco, USA) with $10 \%$ fetal calf serum (TBD Science, China). These autogeneic tumor cells were defined as ATCs. Peripheral blood lymphocytes (PBMCs) were isolated by Ficoll density gradient centrifugation. PBMCs were plated in RPMI-1640 for $3 \mathrm{~h}$ at $37^{\circ} \mathrm{C}$. The cells which did not adhere were mostly lymphocytes and were cultured in RPMI-1640 containing $200 \mathrm{U} / \mathrm{ml}$ recombinant human IL-2 (Proptech, USA) and 10\% human AB serum (TBD Science). Dendritic cells (DCs) were induced from the cord blood hematopoietic stem cells (HSCs) by GM-CSF and IL-4. Briefly, $50 \mathrm{ml}$ cord blood was obtained from healthy parturient and cell components were isolated by Ficoll density gradient centrifugation. The cells in the Ficoll density gradient were plated in RPMI-1640 for $3 \mathrm{~h}$ at $37^{\circ} \mathrm{C}$ and the adhere cells which were mostly HSCs were cultured in RPMI-1640 containing $100 \mathrm{ng} / \mathrm{ml}$ granulocyte-macrophage colony stimulating factor (GM-CSF, Proptech), $50 \mathrm{ng} / \mathrm{ml} \mathrm{IL-4} \mathrm{(Proptech)} \mathrm{and} \mathrm{10 \%} \mathrm{human} \mathrm{AB} \mathrm{serum.} \mathrm{TNF-} \alpha$ $(2.5 \mathrm{ng} / \mathrm{ml})$ (Proptech) was added to the RPMI-1640 on the 5th day of the culture procedure. DCs induced from cord blood HSCs were harvested on the 7 th day.

Stimulation of PBMCs by ascites-derived exosomes. DCs $\left(3 \times 10^{4}\right)$ were cultured with exosomes derived from $10 \mathrm{ml}$ ascites for $2 \mathrm{~h}$ and defined as DC exo (9). The other DCs cultured without exosomes were defined as DC-. PBMCs were divided into 4 groups. In the group 1 , every 3 PBMCs were co-cultured with $1 \mathrm{DC}^{\mathrm{exo}}$ for 7 days in the RPMI-1640 containing $200 \mu / \mathrm{ml}$ IL-2 and $10 \%$ human AB serum. In the group 2, every 3 PBMCs were co-cultured with DC- for 7 days in the same conditions as group 1 . In the group 3, every $3 \times 10^{4}$ PBMCs were cultured with exosomes derived from $10 \mathrm{ml}$ ascites for 7 days in the same conditions as group 1 . In the group 4, PBMCs cultured without DCs or exosomes for 7 days in the same conditions as group 1. PBMCs in all groups were harvest on the 7 th day of the culture procedures.

The cytotoxic effect of the PBMCs which stimulated by exosomes. ATCs and SKOV3 cells were the target cells (TC). The PBMCs which had been stimulated by exosomes or not were the effector cells (EC). Effector cells were co-cultured with target cells on EC: TC=3:1 or 10:1. The same number of ATCs or SKOV3 cells were cultured alone as control target cells $\left(\mathrm{TC}_{\mathrm{con}}\right)$. The same number of PBMCs were cultured alone as control effector cells $\left(\mathrm{EC}_{\mathrm{con}}\right)$. The same volume of pure RPMI-1640 containing 10\% FBS was used as blank.

All these cells were cultured for $48 \mathrm{~h}$ in RPMI-1640 with $10 \% \mathrm{FBS}$ and $5 \% \mathrm{CO}_{2}$. MTT assay was performed as per the instructions of the CCK- 8 kit. The value of OD in every culture well was measured by photodensitometry (Tecan, Austria). The cytotoxic effect (CE) was calculated by the formula:

(OD of TCcon - OD of blank) - (OD of EC with TC - OD of ECcon) $\mathrm{CE}=\ldots$ - $100 \%$ OD of TCcon - OD of blank

Measurement of IFN- $\gamma$ released by PBMCs stimulated by exosomes or not. When EC+TC, TCcon and ECcon had been cultured for $48 \mathrm{~h}, 100 \mu \mathrm{l}$ culture medium from EC+TC culture, TCcon culture, ECcon culture and the blank wells were absorbed. The levels of IFN- $\gamma$ in the $100 \mu 1$ media were measured by ELISA kit (Bender MedSystems, Austria) as per the instructions of the kit.

\section{Effect of exosomes on anti-tumor immunologic function of $D C s$ and $P B M C s$}

The effect of exosomes on the apoptosis of precursor cells of $D C$ and matured DCs. HSCs in cord blood were gained as described. HSCs $\left(1 \times 10^{6}\right)$ were cultured with exosomes derived from $200 \mathrm{ml}$ ascites for $72 \mathrm{~h}$ in RPMI-1640 containing $100 \mathrm{ng} / \mathrm{ml} \mathrm{GM-CSF}, 50 \mathrm{ng} / \mathrm{ml} \mathrm{IL-4}$ and 10\% human $\mathrm{AB}$ serum. These cells were defined as precursor cells of DC. The same number of HSCs cultured in the same conditions, but without exosomes, was the control. DCs were then induced from HSCs as described. For measuring of apoptosis of DCs, DCs $\left(1 \times 10^{6}\right)$ were cultured with exosomes derived from $200 \mathrm{ml}$ ascites for $72 \mathrm{~h}$ in 
RPMI-1640 and 10\% human AB serum. The same number of DCs cultured in same condition, but without exosomes, was the control. After been cultured for $72 \mathrm{~h}$, both precursor cells of DC or DCs and the control cells were measured for apoptosis by Annexin-V/PI staining kit and FCM. The percentages of the apoptotic cells are shown by $\bar{\chi} \pm$ SD.

The effect of exosomes on the mature process of DCs. Precursor cells $\left(3 \times 10^{4}\right)$ were cultured with exosomes derived from $10 \mathrm{ml}$ ascites, and the same number of precursor cells without exosomes were the control group. All these cells were cultured in RPMI-1640 containing $100 \mathrm{~g} / \mathrm{ml}$ GM-CSF, $50 \mathrm{ng} / \mathrm{ml} \mathrm{IL-4}$ and $10 \%$ human AB serum. TNF- $\alpha(2.5 \mathrm{ng} / \mathrm{ml})$ was added to the RPMI-1640 on the 5th day of the culture procedure in both groups. All the cells were harvested on the 10th day of culture. The surface maskers of HLA-ABC, HLA-DR, CD80, CD86, CD1a, Fas on DCs harvested from both group were measured by mouse anti-human monoclonal fluor-antibodies (eBioscience, USA) of FITC-HLA-ABC, FITC-HLA-DR, FITC-CD80, FITC-CD1a, PE-CD86, PE-

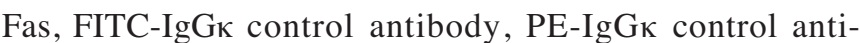
body and FCM.

The effect of exosomes on $\mathrm{CD}^{+}$and $\mathrm{CD} 8^{+}$lymphocytes proportions in PBMCs and FasL expression. PBMCs $\left(3 \times 10^{4}\right)$ were cultured with exosomes derived from $10 \mathrm{ml}$ ascites in RPMI-1640 containing $200 \mathrm{ng} / \mathrm{ml} \mathrm{IL-2}$ and 10\% human AB serum for $72 \mathrm{~h}$. The same number of PBMCs was cultured in the same condition, but without exosomes, as the control. The proportion of $\mathrm{CD}^{+} / \mathrm{CD} 4^{+} \mathrm{T}$ cells and $\mathrm{CD} 3{ }^{+} / \mathrm{CD}^{+} \mathrm{T}$ cells in the groups and their surface masker FasL were measured by mouse anti-human monoclonal fluor-antibodies (eBioscience) of PE-CD3, PE-FasL, FITC-CD4, FITC-CD8 and FCM.

Then PBMCs and DCs were co-cultured according to PBMCs: DCs=3:1 in RPMI-1640 containing IL-2, $200 \mathrm{ng} / \mathrm{ml}$ and $10 \%$ human $\mathrm{AB}$ serum for $72 \mathrm{~h}$. In this co-culture system, PBMCs $\left(3 \times 10^{4}\right)$ were cultured with exosomes derived from $10 \mathrm{ml}$ ascites on day $1 \mathrm{st}$ of the culture procedure the test group, and the PBMCs without exosomes were the control group. The proportions of $\mathrm{CD} 3^{+} / \mathrm{CD} 4^{+} \mathrm{T}$ cells and $\mathrm{CD}^{+} / \mathrm{CD}^{+} \mathrm{T}$ cells in both groups were measured by monoclonal fluor-antibodies and FCM as above.

The effect of exosomes on the apoptosis of PBMCs. PBMCs $\left(3 \times 10^{4}\right)$ were cultured with exosomes derived from $10 \mathrm{ml}$ ascites for $72 \mathrm{~h}$. The same number of PBMCs cultured on the same condition but without exosomes was the control group. Apoptosis of PBMCs in both groups were measured by Annexin-V/PI staining kit and FCM.

The detection of FasL and TRAIL on exosomes. Exosome suspension $(20 \mu \mathrm{l})$ was used to detected FasL and TRAIL by Western blot analysis. The apoptosis signature molecule FasL on exosomes was detected by Western blot analysis using $12 \%$ SDS-PAGE and polyclonal antibody to FasL (Santa Cruz Biotechnology) and IEM. The apoptosis molecule TRAIL on exosomes was detected by Western blot analysis using $12 \%$ SDS-PAGE and polyclonal antibody to TRAIL (Santa Cruz Biotechnology).

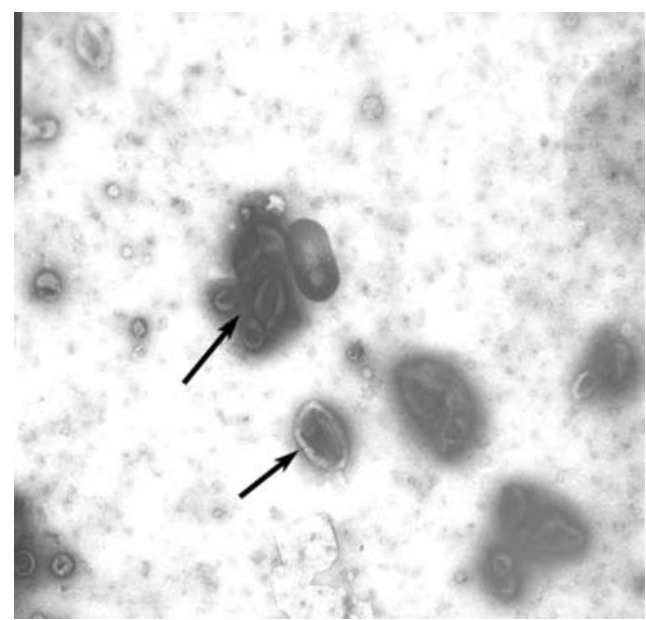

Figure 1. Exosome-like vesicles in the ascites from ovarian cancer patients (x3000; bar, $200 \mathrm{~nm})$.

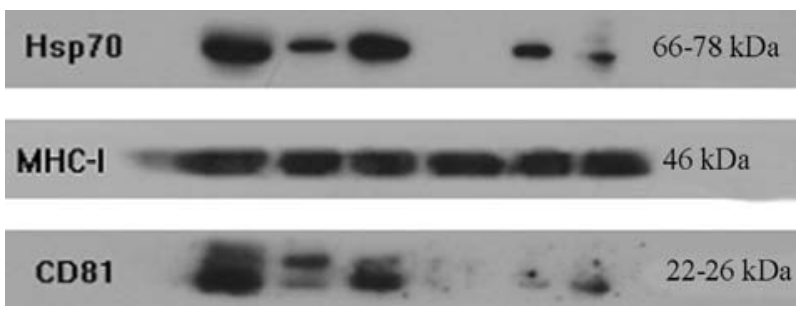

Figure 2. HSP70, MHC-I and CD81 were found in the suspensions of exosome-like vesicles.

Antibody blockade of apoptosis. Different volume of human FasL antagonistic antibody NOK-2 (BD PharMingen, USA) was added into the co-cultures of exosomes and DCs or PBMCs, and then apoptosis of DCs or PBMCs was reevaluated by Annexin-V/PI and FCM.

The detection of TRAIL receptors DR4 and DR5 on DCs and $P B M C s$. DCs and PBMCs $\left(3 \times 10^{4}\right)$ were cultured with exosomes derived from $10 \mathrm{ml}$ ascites or not. The TRAIL receptors 4 (death receptor 4 , DR4) and receptor 5 (death receptor 5, DR5) on surface of DCs and PBMCs were detected by fluor-antibodies PE-TRAIL1 (eBioscience), PE-TRAIL2 (eBioscience) and FCM.

Statistical methods. The data were analyzed by statistical software SPSS 13.0. Student's t-test was used for comparison of numeration data and $\chi^{2}$ test was used for rate comparison between groups.

\section{Results}

Purification and identification of exosomes. We assembled ascites from 41 ovarian cancer patients and harvested exosome-like vesicles from ascites in 35 patients $(85.4 \%)$. These vesicles were round or cup-like and 30-100 $\mathrm{nm}$ in diameter (Fig. 1).

We found HSP70, MHC-I and CD81 molecular signatures on the suspensions of exosome-like vesicles (Fig. 2). 


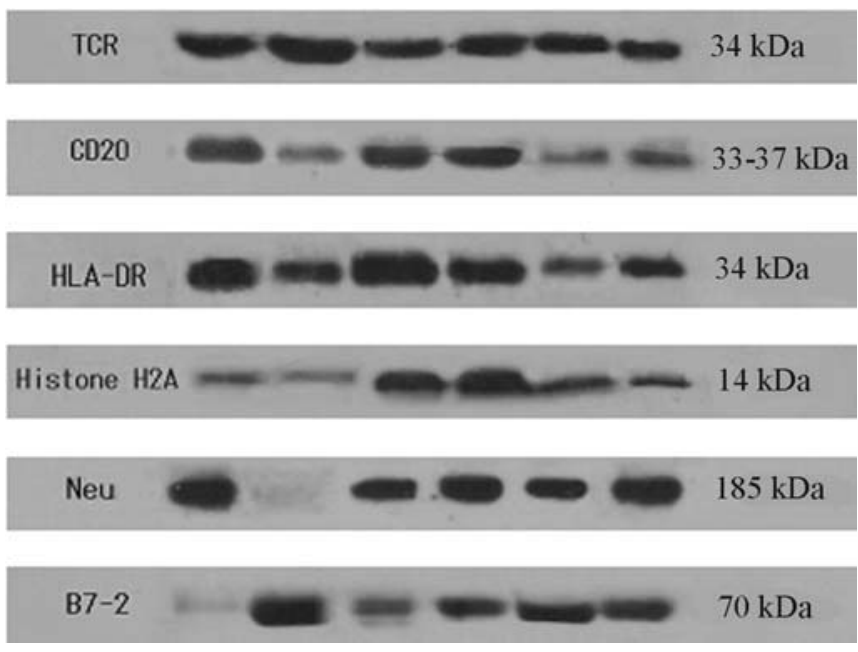

Figure 3. TCR, CD20, HLA-DR, Histone $\mathrm{H}_{2} \mathrm{~A}, \mathrm{~B} 7-2$ and Neu were tested in the suspension of exosomes by Western blot analysis.
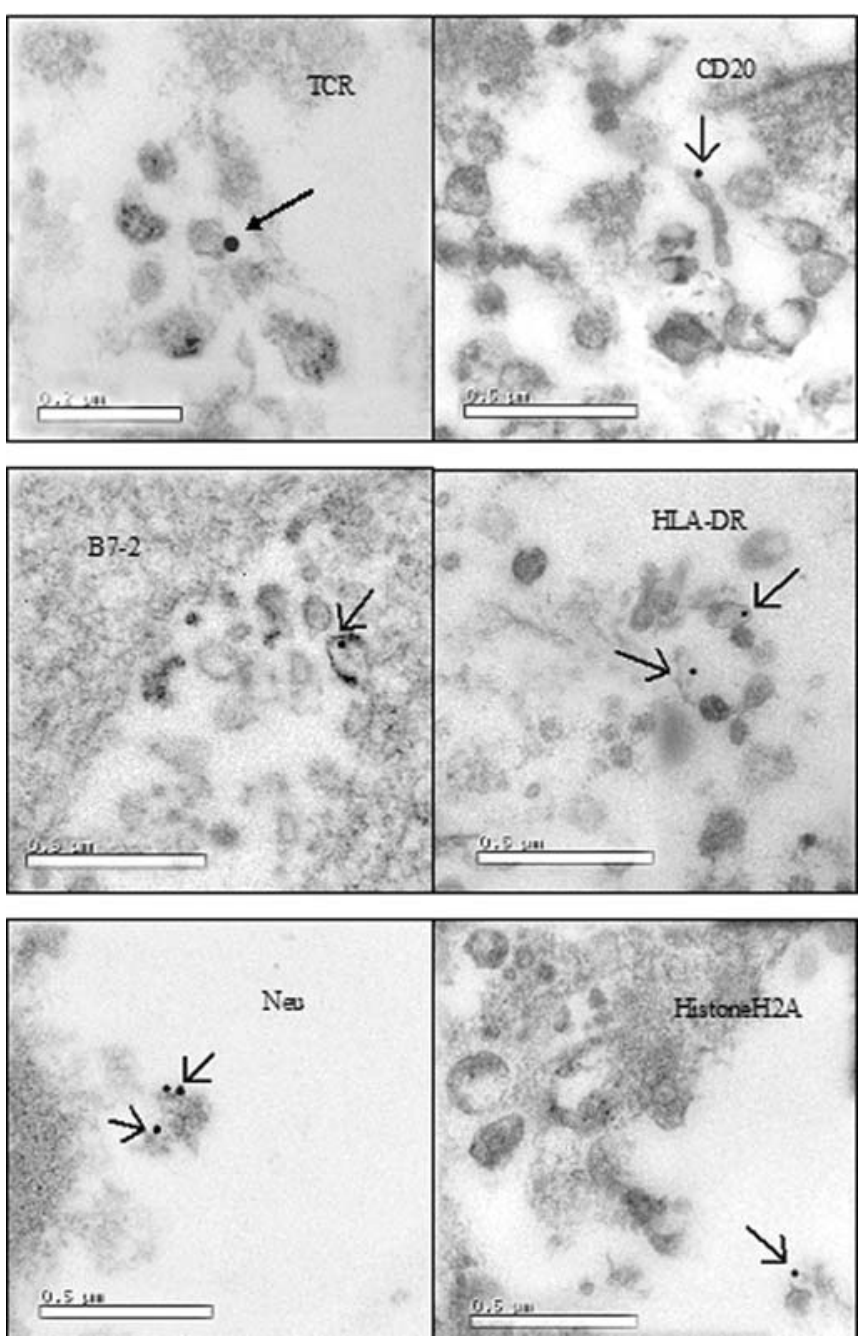

Figure 4. TCR, CD20, HLA-DR, Histone $\mathrm{H}_{2} \mathrm{~A}, \mathrm{~B} 7-2$ and Neu were detected in the suspension of exosomes by IEM.

Detection of the exosome expressing antigens. We tested exosomes suspensions purified from 6 patients and found TCR, CD20, HLA-DR, and Histone $\mathrm{H}_{2} \mathrm{~A}$ could be detected

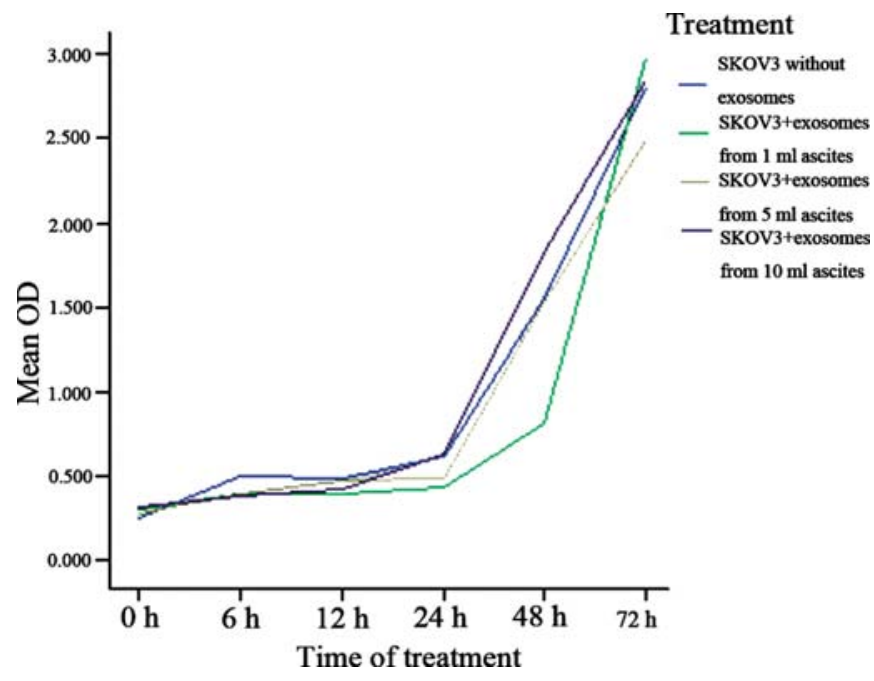

Figure 5. The growth curve of ovarian cell line SKOV3 cultured with or without exosomes.

in all $(100 \%)$ the exosome suspensions. B7-2 and Neu could be detected in 5 patients $(83.3 \%$ ) (Fig. 3).

We also found TCR, CD20, HLA-DR, Histone $\mathrm{H}_{2} \mathrm{~A}, \mathrm{~B} 7-2$ and Neu in the surface of exosomes by IEM. Among these molecules, TCR and CD20 were in all the 6 suspensions (100\%), B7-2, HLA-DR and Neu were in 5 suspensions (83.3\%), and Histone $\mathrm{H}_{2} \mathrm{~A}$ was in 4 suspensions (66.7\%) (Fig. 4).

The effect of the ascites-derived exosome on the growth and apoptosis of ovarian cancer cells. No matter how many exosomes were added into the SKOV3 cell culture system, the growth curve of SKOV3 cells was not affected (Fig. 5).

By FCM, it was shown that exosomes had no effect on the percentages of apoptosis and necrosis of ATCs and SKOV3 cells (Fig. 6).

We did not find any morphological change when ATCs and SKOV3 cells cultured with exosomes were investigated with light microscopy (Fig. 7).

The in vitro anti-ovarian cancer effect of the PBMCs stimulated by ascites-derived exosomes. We isolated PBMCs from both ovarian cancer patients and healthy volunteers. The in vitro anti-ovarian cancer cells effects of PBMCs that were presented by cytotoxic effect (CE), both in SKOV3 cells and ATCs, are shown in Table I. The results of CE are showed by $\bar{\chi} \pm \mathrm{SD}$.

PBMCs which were stimulated by DCs plus exosomes had the lowest ability to kill the cancer cells. The PBMCs stimulated by pure DCs, or by pure exosomes, or by nothing had the same ability to kill cancer cells (Fig. 8).

PBMCs from ovarian cancer patients and healthy volunteers showed similar results of CE (Fig. 9).

Measurement of IFN- $\gamma$ released by PBMCs stimulated by exosomes or not. We measured the INF- $\gamma$ levels in the media from the different PBMC cultured wells and measured the change of IFN- $\gamma$ levels before PBMCs cocultured with ovarian cancer cells and after. The PBMCs 

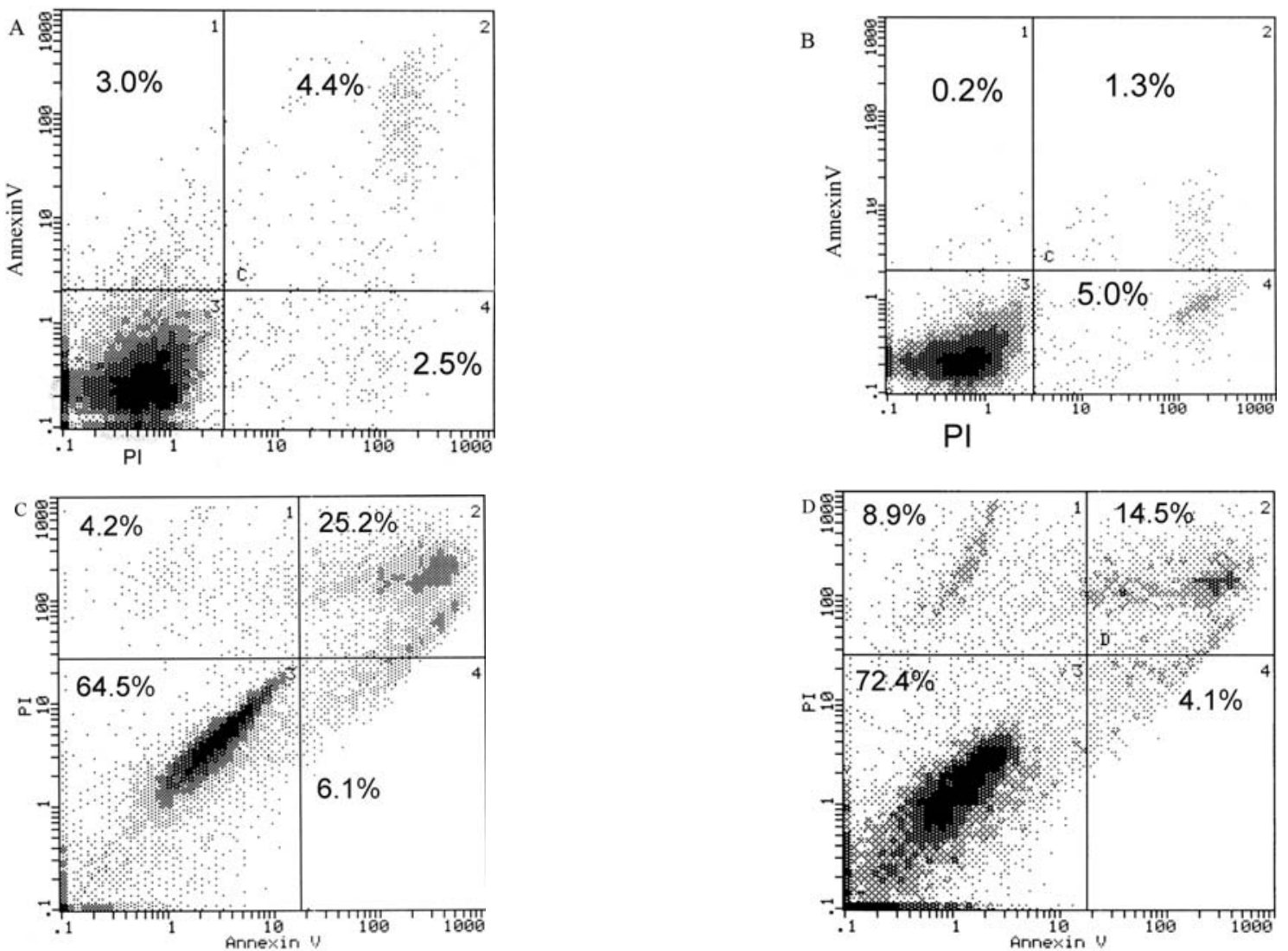

Figure 6. (A) Apoptosis of SKOV3 cells cultured without exosomes. (B) Apoptosis of SKOV3 cells cultured with exosomes. (C) Apoptosis of ATCs cultured without exosomes. (D) Apoptosis of ATCs cultured with exosomes.
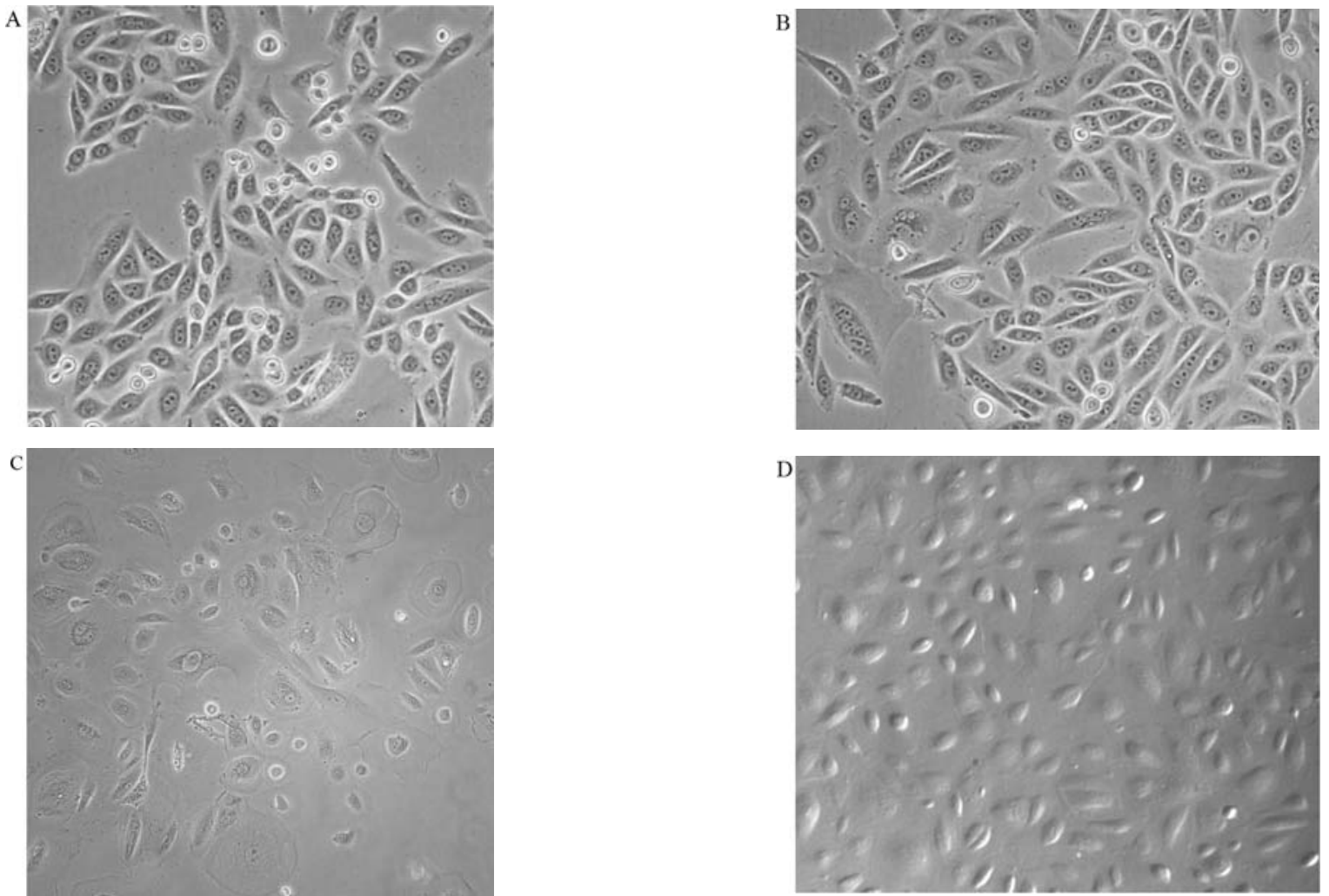

Figure 7. (A) SKOV3 cells cultured without exosomes (magnification x100). (B) SKOV3 cells cultured with exosomes for 48 h (magnification x100). (C) ATCs cultured without exosomes (magnification x100). (D) ATCs cultured with exosomes for $48 \mathrm{~h}$ (magnification x100). 
Table I. The in vitro anti-ovarian cancer cells cytotoxic effect (CE) of PBMCs on SKOV3 cells and ATCs.

\begin{tabular}{lcccccc}
\hline Origins of PBMCs & Target cells & EC:TC & DC ${ }^{\text {exo }}+$ PBMCs & DC - PBMCs & Exosomes + PBMCs & PBMCs \\
\hline $\begin{array}{l}\text { Ovarian cancer } \\
\text { patients }\end{array}$ & ATCs & $3: 1$ & $23.9 \pm 33.8$ & $43.7 \pm 61.8$ & $42.3 \pm 59.8$ & $47.1 \pm 35.9$ \\
& & $10: 1$ & $72.0^{\mathrm{a}}$ & 100.0 & $\mathrm{NA}^{\mathrm{b}}$ & $\mathrm{NA}^{\mathrm{b}}$ \\
& SKOV3 & $3: 1$ & $3.8 \pm 5.2$ & $6.2 \pm 9.0$ & $13.9 \pm 21.5$ & $11.6 \pm 23.1$ \\
& & $10: 1$ & $5.8 \pm 4.8$ & $16.4 \pm 16.6$ & $\mathrm{NA}^{\mathrm{b}}$ & $\mathrm{NA}^{\mathrm{b}}$ \\
Healthy volunteers & ATCs & $3: 1$ & $0.4 \pm 0.8$ & $14.3 \pm 22.2$ & $28.7 \pm 44.7$ & $12.9 \pm 21.3$ \\
& & $10: 1$ & $0.0 \pm 0.0$ & $0.0 \pm 0.0$ & $0.0 \pm 0.0$ & 38.8 \\
& SKOV3 & $3: 1$ & $2.0 \pm 3.0$ & $5.0 \pm 8.5$ & $0.2 \pm 0.4$ & $6.4 \pm 7.1$ \\
& & $10: 1$ & $4.6 \pm 9.3$ & $22.1 \pm 21.1$ & 14.2 & 0.0 \\
\hline
\end{tabular}

${ }^{\mathrm{a}}$ Test was performed only in one case. ${ }^{\mathrm{b}}$ Test was not performed due to the lack of effector cells.

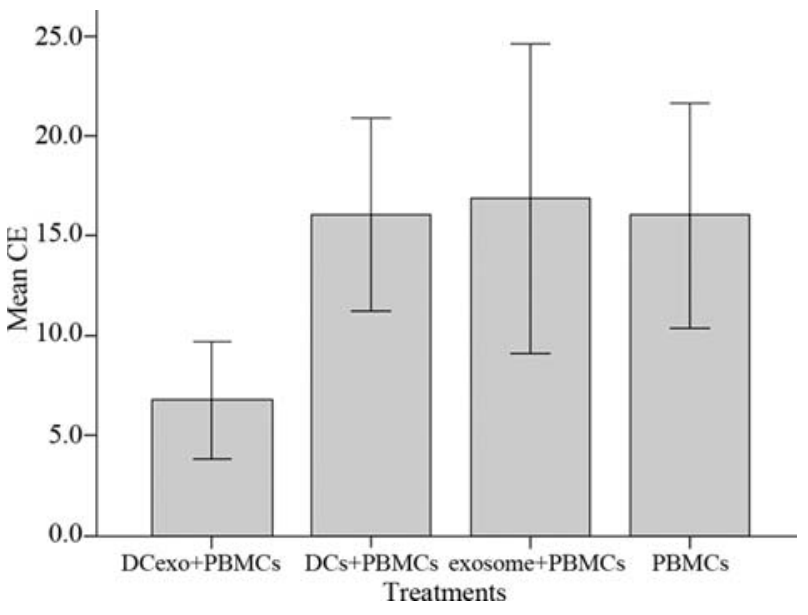

Figure 8 . The cytotoxic effects of PBMCs treated by different methods.

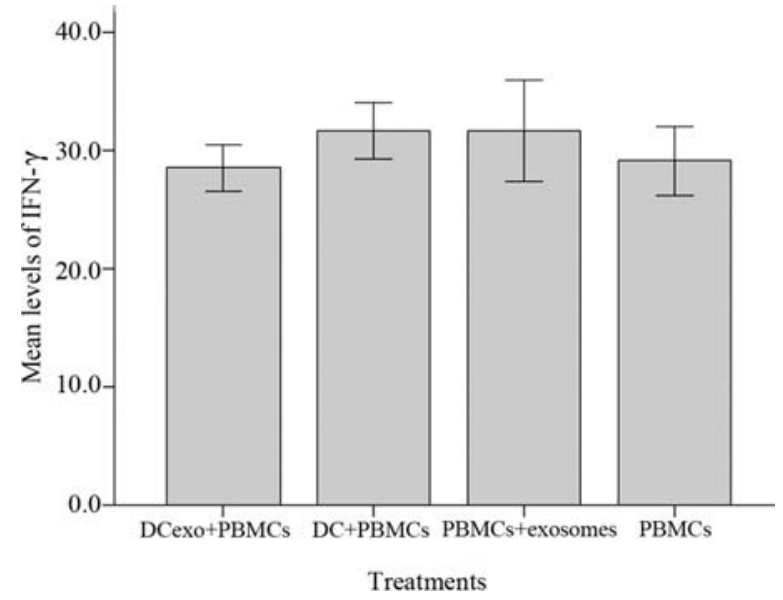

Figure 10. The IFN- $\gamma$ levels released by PBMCs of different treatments.

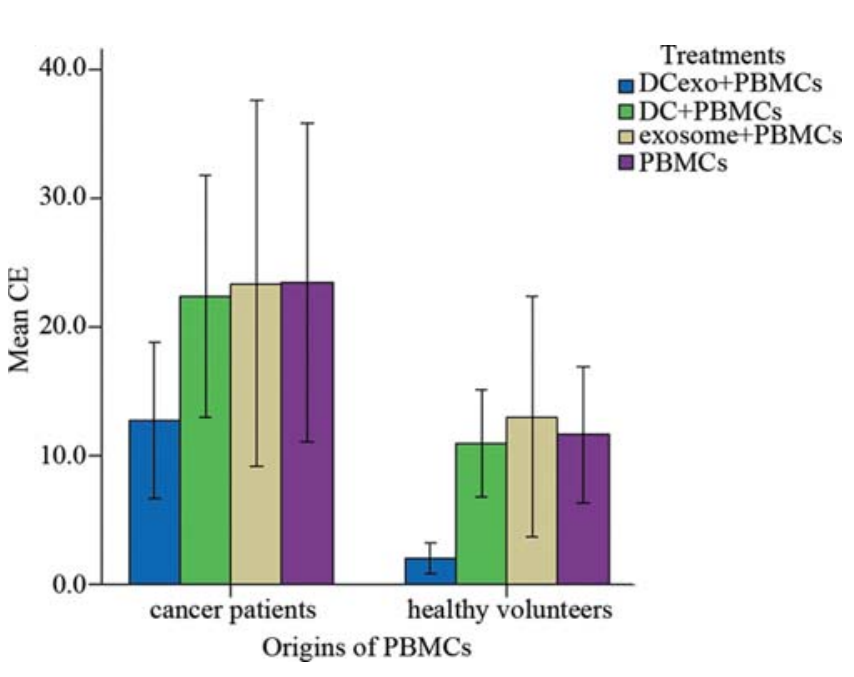

Figure 9. The cytotoxic effects of PBMCs of different origins. stimulated by DCexo released slightly less INF- $\gamma$ than the PBMCs stimulated by DC- (Fig. 10). If we compared the INF- $\gamma$ levels before PBMCs co-cultured with SKOV3 cells

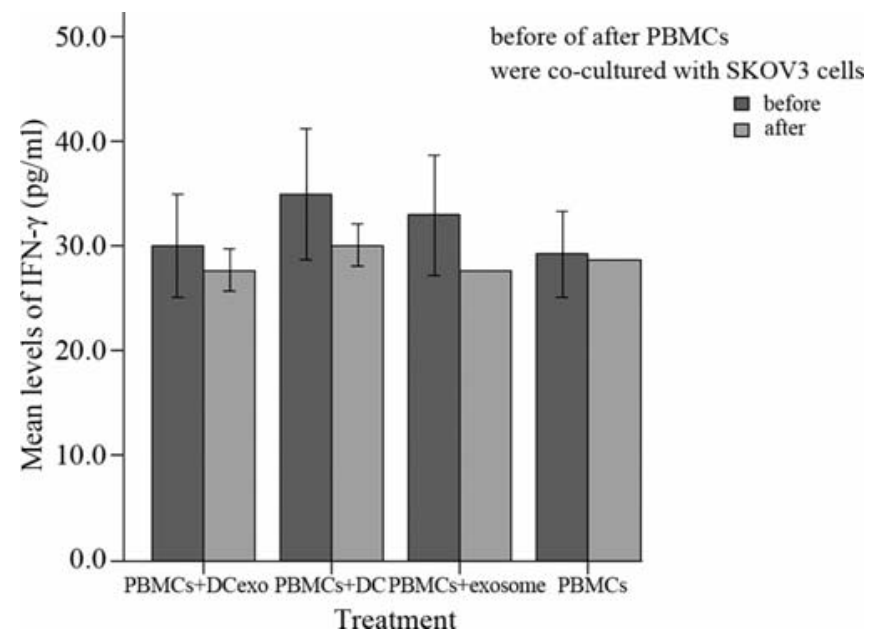

Figure 11. The changes of levels of IFN- $\gamma$ before and after PBMCs were co-cultured with SKOV3 cells.

and after, we found that no matter how the PBMCs were treated, the INF- $\gamma$ levels had no change after PBMCs cocultured with SKOV3 cells (Fig. 11). 

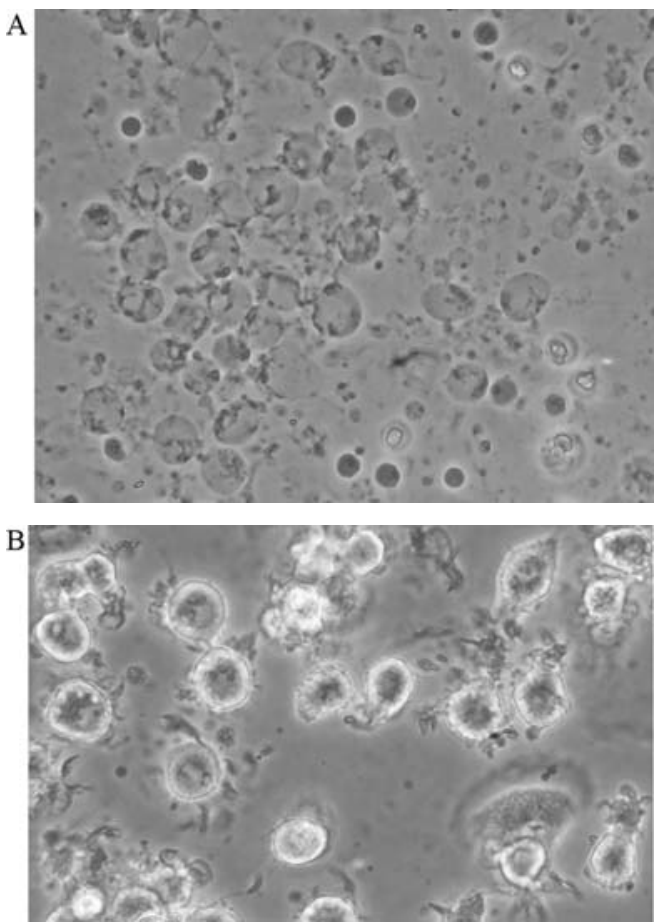

Figure 12. (A) The precursor cells of DC were cultured with exosomes for $48 \mathrm{~h}$ (x400). (B) The precursor cells of DC were cultured without exosomes for $48 \mathrm{~h}(\mathrm{x} 400)$.
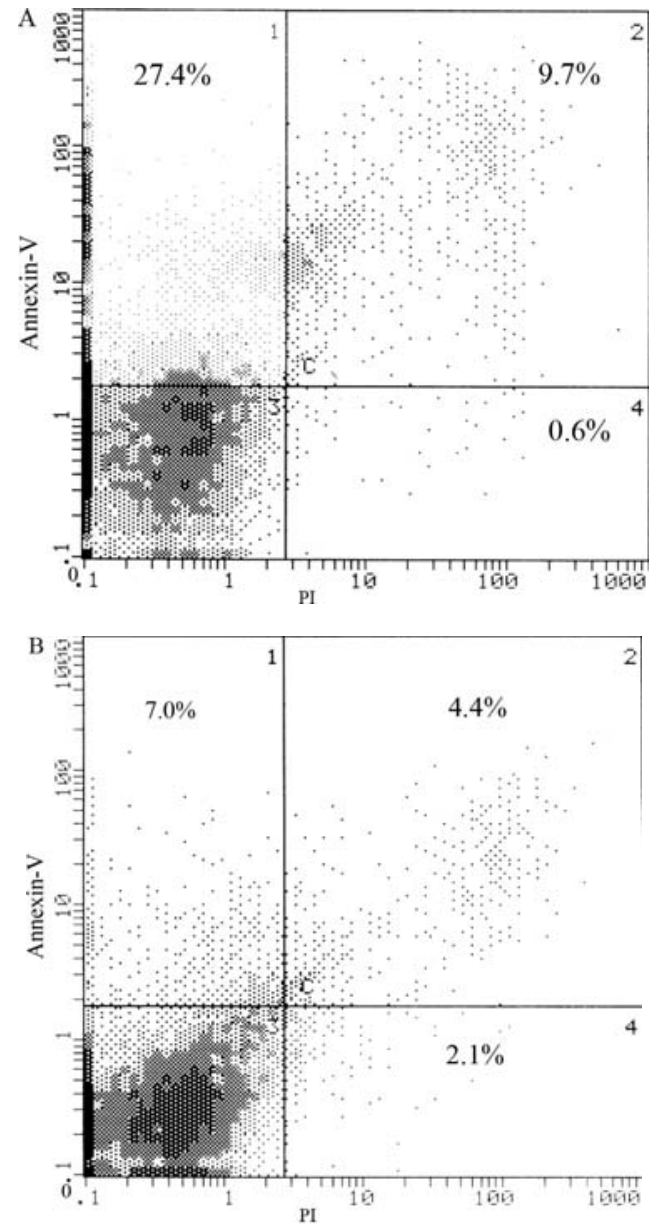

Figure 13. (A) The percentage of apoptotic cells in the precursor cells of DC with exosomes. (B) The percentage of apoptotic cells in the precursor cells of DC without exosomes.

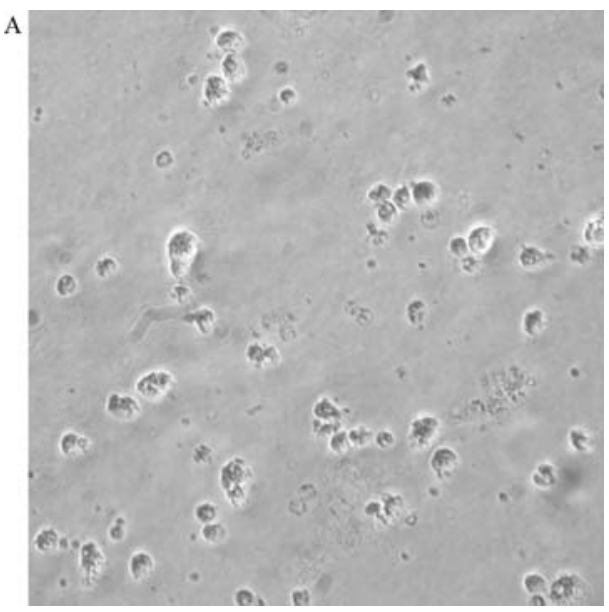

B

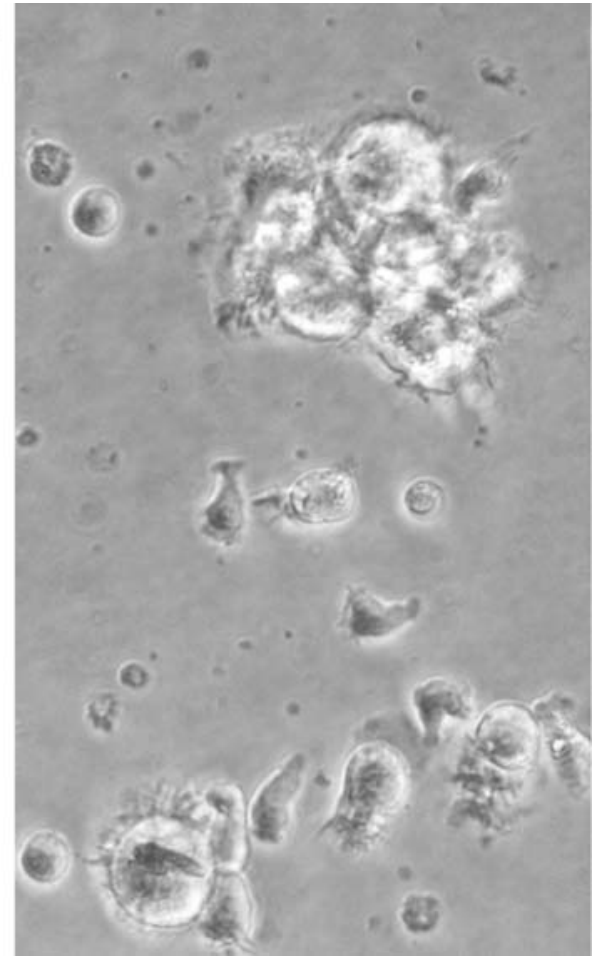

Figure 14. (A) DCs were cultured with exosomes for 48 h (x400). (B) DC were cultured without exosomes for $48 \mathrm{~h}$ (x400).

Effect of exosomes on anti-tumor immunologic function of $D C s$ and $P B M C s$

The effect of exosomes on the apoptosis of precursor cells of $D C$ and matured DCs. When precursor cells of DC were cultured with exosomes for $48 \mathrm{~h}$, we found some cells presented the appearance of apoptosis by microscopy, but the control precursor cells of DC cultured without exosomes had no appearance of apoptosis (Fig. 12). The percentages of the apoptotic cells in the precursor cells cultured with exosomes were $10.6 \pm 14.6 \%$ and that in the control cells $3.9 \pm 3.5 \%$ (Fig. 13).

When DCs were cultured with exosomes for $48 \mathrm{~h}$, we also found some DCs presented apoptosis, but the control cells had no appearance of apoptosis (Fig. 14). The percentages of the apoptosis cells in the DCs cultured with exosomes were $18.8 \pm 12.6 \%$ and that in the control cells were $12.1 \pm 8.6 \%$ (Fig. 15). 

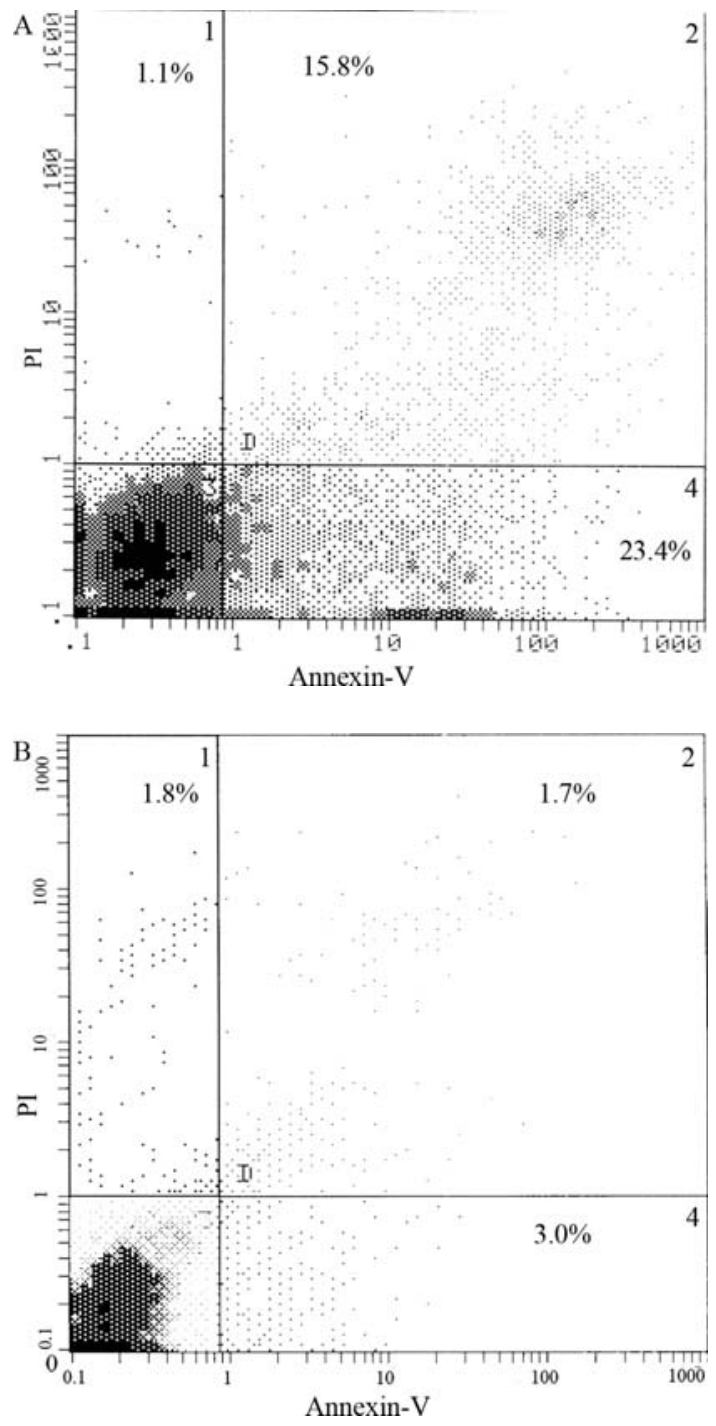

Figure 15. (A) The percentage of apoptotic cells in the DCs with exosomes. (B) The percentage of apoptotic cells in the DCs without exosomes.

The effect of exosomes on the maturation process of DCs. Whether the precursor cells of DC were cultured with exosomes or not, the expressions of molecular markers CD80, CD86, HLA-ABC, HLA, DR that reflected the antigen presentation ability of DC, CD1a that reflected the maturation of DC, and Fas/FasL that were related to apoptosis were similar on both the DCs induced from the precursor cells with exosomes and DCs from precursor cells without exosomes (Fig. 16).

The effect of exosomes on $\mathrm{CD}^{+}$and $\mathrm{CD} 8^{+}$lymphocytes proportions in PBMCs and FasL expressing. We found that the proportion of $\mathrm{CD}^{+} / \mathrm{CD}^{+}$cells in PBMCs cultured with exosomes was $68.1 \pm 14.3 \%(n=3)$ and that in PBMCs without exosomes was $57.8 \pm 18.1 \%(n=3)$. The proportion of $\mathrm{CD}^{+} / \mathrm{CD} 8^{+}$cells in PBMCs cultured with exosomes was $32.0 \pm 5.0 \%(\mathrm{n}=3)$ and that in PBMCs without exosomes was $27.8 \pm 6.1 \%(\mathrm{n}=3)$. The ratio of $\mathrm{CD} 4^{+} / \mathrm{CD}^{+}$cells in PBMCs cultured with exosomes was $2.4 \pm 0.85$ and that in PBMCs without exosomes was $2.0 \pm 0.4$. The expression of FasL on

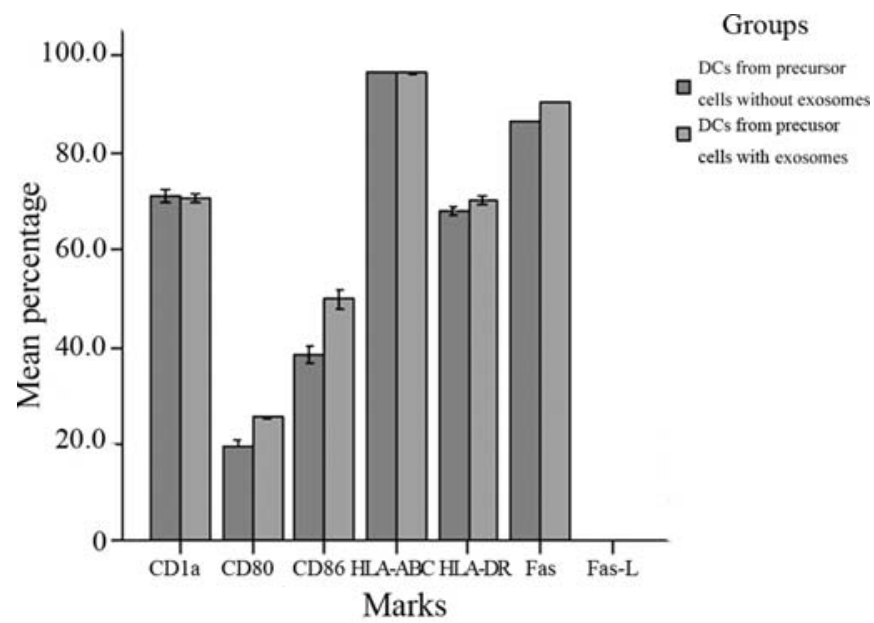

Figure 16. The surface markers expressed on DCs from precursor cells in the presence or absence of exosomes.

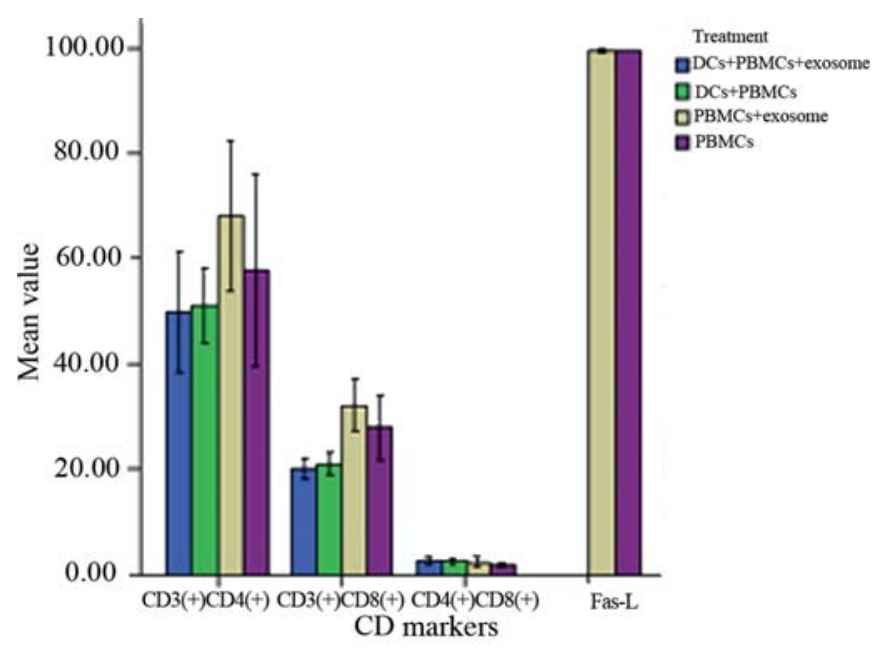

Figure 17. The effect of exosomes on the CD markers expressing in PBMCs with different treatments.

PBMCs with exosomes was $99.4 \pm 0.4 \%(\mathrm{n}=3)$ and that on PBMCs without exosomes was $99.5 \pm 0.0 \%(n=3)$.

Because lymphocytes could be activated when DCs existed, we considered the effect of the existence of DC on the results. When PBMCs were co-cultured with DCs, the proportion of $\mathrm{CD}^{+} / \mathrm{CD}^{+}$cells in PBMCs with exosomes was $50.0 \pm 20.0 \%(n=3)$ and that in PBMCs without exosomes was $51.1 \pm 12.4 \%(n=3)$. The proportion of $\mathrm{CD}^{+} / \mathrm{CD} 8^{+}$cells in PBMCs cultured with exosomes was $20.1 \pm 3.6 \%(n=3)$ and that in PBMCs without exosomes was $21.0 \pm 3.9 \%(n=3)$. The ratio of $\mathrm{CD}^{+}$cells $/ \mathrm{CD} 8^{+}$cells in PBMCs with exosomes was $2.6 \pm 1.3$ and that in PBMCs without exosomes was $2.5 \pm 1.0$ (Fig. 17).

The effect of exosomes on the apoptosis of PBMCs. We found that the effects of exosomes on the apoptosis of PBMCs were different in different tests. Among 5 independent tests, we found the apoptosis of PBMCs was increased when exosomes existed in 2 tests, the apoptosis was decreased in 1 test and the apoptosis had no significant change in 2 tests (Table II). 
Table II. The effect of exosomes on the apoptosis of PBMCs.

\begin{tabular}{llrrrr}
\hline \multirow{2}{*}{ Groups } & \multicolumn{4}{c}{ Tests } \\
\cline { 2 - 6 } & Test 1 & Test 2 & Test 3 & Test 4 & Test 5 \\
\hline PBMCs cultured with exosomes & $19.3^{\mathrm{a}}$ & 36.3 & 3.8 & 2.4 & 6.9 \\
PBMCs cultured without exosomes & 22.2 & 27.2 & 11.2 & 2.9 & 3.8 \\
\hline
\end{tabular}

${ }^{a}$ The percentage of the apoptotic cells.

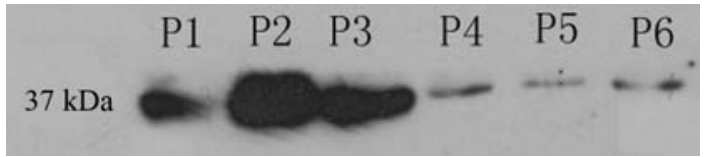

Figure 18. The expression of FasL on the exosome suspension (12\% SDS-PAGE, $n=6$ ).

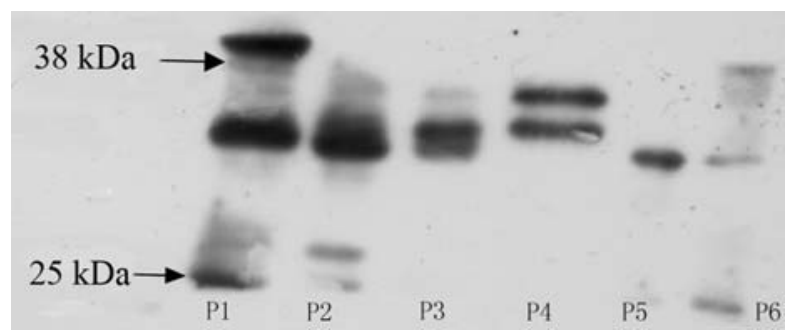

Figure 19. The expression of TRAIL on the exosome suspension (12\% SDSPAGE, $n=6)$.

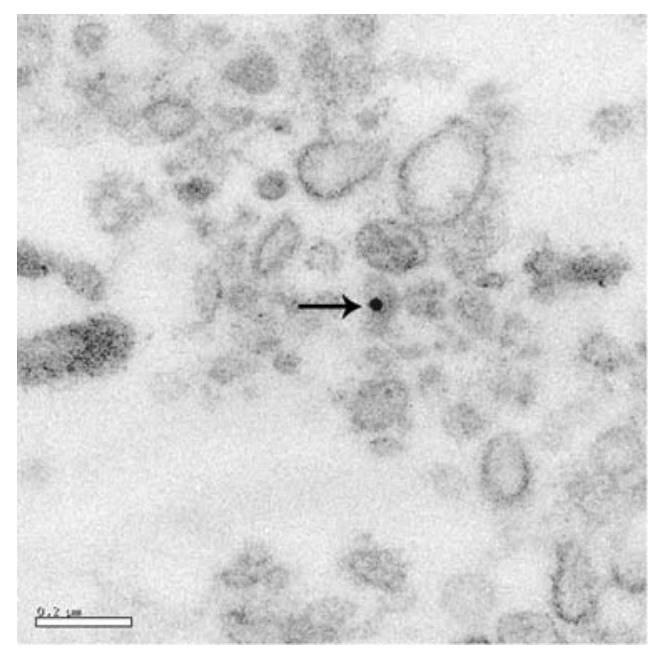

Figure 20. FasL located on the surface of exosomes (bar, $200 \mathrm{~nm}, 80 \mathrm{KV}$, $\mathrm{x} 100,000)$.

The detection of FasL and TRAIL on exosomes. By Western blot analysis, the exosomes suspension had the expression of FasL and TRAIL. As known, both FasL and TRAIL have 2 forms: the membrane-combined and the soluble form. These forms have different molecular weights $(\mathrm{Mw})$. We found the signature bands of both FasL and TRAIL were on the Mw of

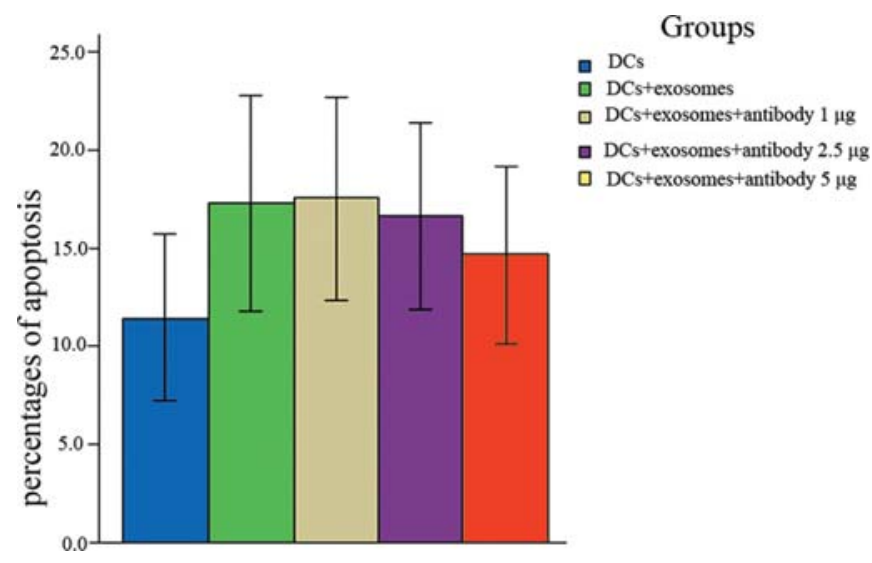

Figure 21. Antibody blockade of apoptosis on DCs that was induced by exosomes.

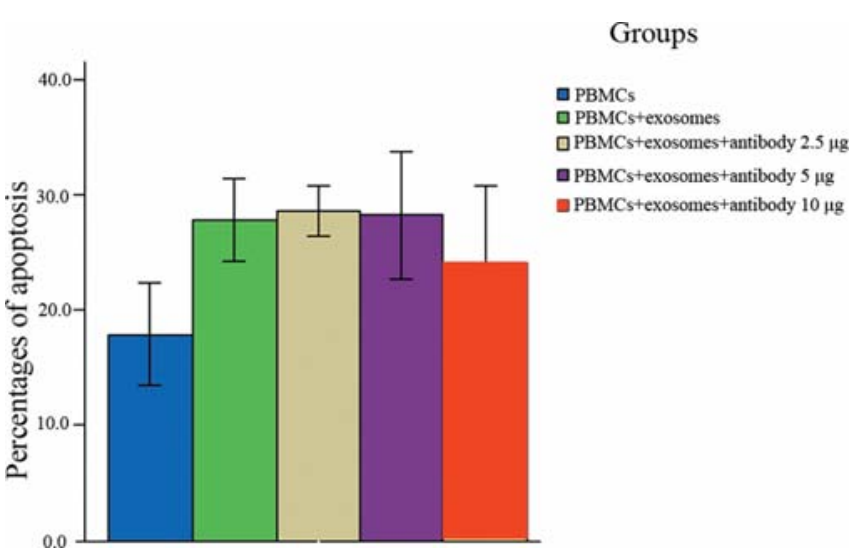

Figure 22. Antibody blockade of apoptosis on PBMCs that was induced by exosomes.

the membrane-combined form (Figs. 18 and 19). By IEM, FasL was observed on the exosomes (Fig. 20).

Antibody blockage of apoptosis on DCs and PBMCs. When we added the human FasL antagonistic antibody NOK-2 into the DCs cultured with exosomes or not, among 3 independent tests, we found that anti-FasL antibody could decrease the percentage of apoptosis of DCs induced by exosomes, but the antibody could not block the apoptosis completely (Fig. 21).

Among 3 independent tests, anti-FasL antibody could also decrease the percentage of apoptosis of PBMCs 

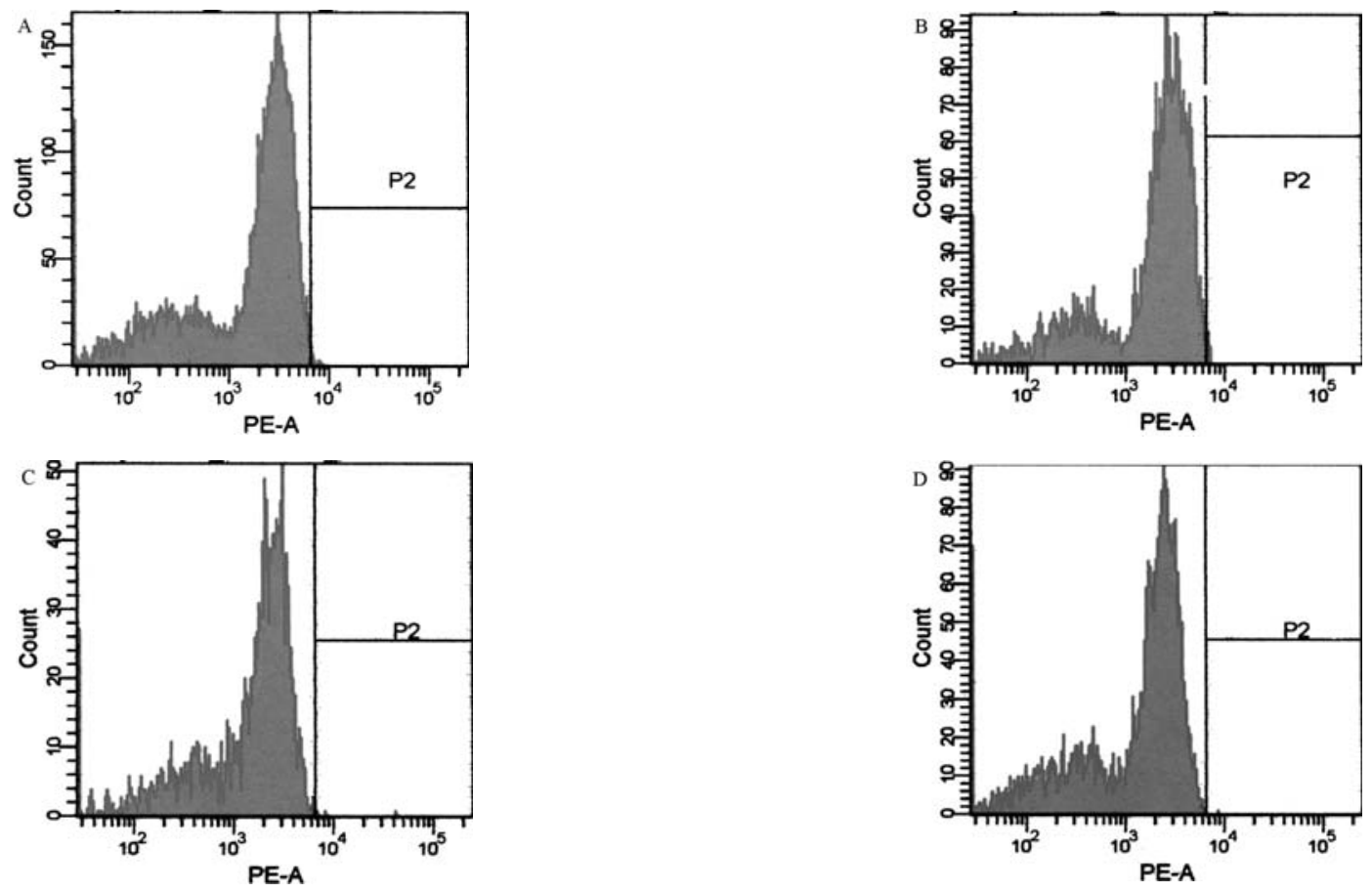

Figure 23. (A) The expression of TRAIL receptor DR4 on surface of DCs. (B) The expression of TRAIL receptor DR5 on surface of DCs. (C) The expression of TRAIL receptor DR4 on surface of DCs cultured with exosomes. (D) The expression of TRAIL receptor DR5 on surface of DCs cultured with exosomes.
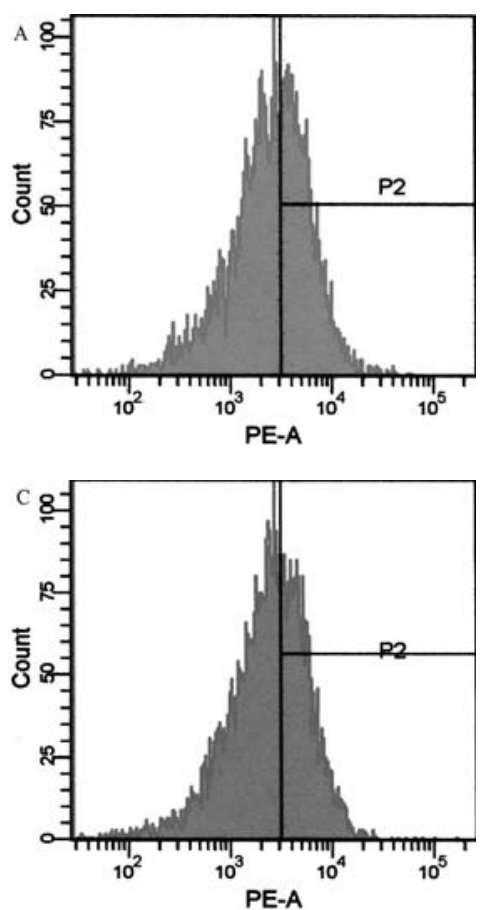
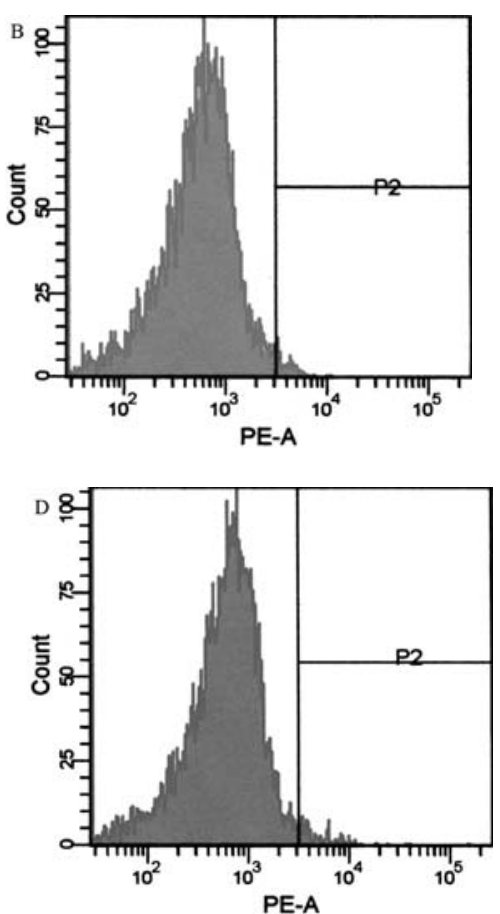

Figure 24. (A) The expression of TRAIL receptor DR4 on surface of PBMCs. (B) The expression of TRAIL receptor DR5 on surface of PBMCs. (C) The expression of TRAIL receptor DR4 on surface of PBMCs cultured with exosomes. (D) The expression of TRAIL receptor DR5 on surface of PBMCs cultured with exosomes.

induced by exosomes, but could not block the apoptosis completely either (Fig. 22).

The detection of TRAIL receptors DR4 and DR5 on DCs and PBMCs. By FCM, we found the expression of TRAIL receptor DR4 and DR5 on DCs were $3.70 \pm 2.70 \%$ and $9.40 \pm 6.46 \%$, respectively ( $=3$, Fig. 23 ). When DCs were cultured with exosomes for $72 \mathrm{~h}$, the expression of DR4 and DR5 on DCs were $5.57 \pm 3.52 \%$ and $7.00 \pm 4.20 \%$, respectively ( $\mathrm{n}=3$, Fig. 23 ). 
The results of PBMCs were similar to that of DCs. We found the expression of DR4 and DR5 on PBMCs was $16.00 \pm 12.15 \%$ and $1.10 \pm 0.21 \%$, respectively (n=3, Fig. 24). When PBMCs were cultured with exosomes for $72 \mathrm{~h}$, the expression of DR4 and DR5 was $16.20 \pm 10.47 \%$ and $1.40 \pm 0.35 \%$, respectively ( $n=3$, Fig. 24$)$.

\section{Discussion}

The origin of the ascites-derived exosomes in patients of ovarian cancer. It is known that many kinds of cells can produce exosomes, and the exosomes from different cells may have different protein components $(9,13,14)$. Bard et al (15) found that the exosomes in the malignant pleural fluid might be from B cell, T cell, DC and tumor cell. Andre et al (9) found that exosomes in the ascites from melanoma, ovarian cancer or breast cancer patients expressed tumor antigen Mart1 and HER2/neu, which indicated that these exosomes might come from tumor cells.

Our study showed there were immunological cell antigens on the exosomes, which meant that the ascites-derived exosomes could come from immunological cells. In vitro studies have shown MHC-II molecules enriched on the exosomes that were purified from specific APC $(16,17)$, B72 enriched on the exosomes purified from DCs $(18,19)$, TCR enriched on the exosomes purified from $T$ cells $(20,21)$ and CD20/BCR enriched on the exosomes purified from B cells (22). By Western blot analysis and IEM, we found there were B7-2, HLA-DR, CD20 and TCR existing in the suspension of ascites-derived exosomes, indicating that the exosomes derived from ovarian cancer patients might be from DC, $\mathrm{T}$ cell and B cells. However, these exosomes also might be from other cells such as mast cells that can secrete exosomes expressing CD86 and MHC-II (23). Because ovarian cancer cells also can secrete exosomes expressing HLA-DR (4), we need to explore more specific molecular markers to identify the exosomes from immunological cells, mast cells or tumor cells.

Exosomes can express tumor antigens, therefore exosomes may be from tumor cells. Andre et al (9) detected the signal of Her2/neu on ascites-derived exosomes from ovarian cancer patients by Western blot analysis. By IEM, we found Her2/neu and CA125 located on the surface of exosomes, so we concluded there were exosomes from tumor cells in the ascites of ovarian cancer patients. The significance of these exosomes from tumor cells was not clear. The influence of these exosomes to host anti-tumor immunology and whether they have relation to disease progression and prognosis, like Her2/neu and CA125, still need further study.

Previously, it was thought that proteins in the cell nucleus, such as histone proteins had no expression on the exosomes (24). But recent research has shown that exosomes also have certain nuclear proteins. Mor-Vaknin et al (25) found in the patients of juvenile arthritis, that the synovial fluid had exosomes derived from macrophage expressing DNA binding protein DEK. In the ascites of the ovarian cancer patients, Taylor et al (11) found exosomes expressing nucleolin B23 that related to the mature of ribosome and cell proliferation. Taylor et al thought exosomes could transfer this autoantigen to the cell surface exposing the immunological cells. Histone A2 is a protein marker of apoptosis. We used Western blot analysis and IEM to find whether Histone A2 existed in the suspension of exosomes and located on the surface of exosomes. But, we still do not know how and why Histone A2 was on the exosomes. Histone A2 might also be from the apoptotic body. But the appearance of apoptotic body is very different from that of exosomes, and the volume of apoptotic bodies are larger than that of exosomes. For further research, both antibodies to exosomes markers and that to histone protein can be used simultaneously to combine with exosomes. If both antibodies can be combined with exosomes, we could conclude definitely that exosomes express nuclear protein Histone A2.

The effect of the ascites-derived exosome on the growth and apoptosis of ovarian cancer cell. There is no report that exosome have direct and definite effect on ovarian cancer cells. In our study, the different volumes of exosomes had no effect on the growth of SKOV3 cells. And by FCM, the apoptosis of SKOV3 cells and ATCs had no significant change before exosomes existence and after exosome existence. By microscopy, we did not find that exosomes affected the appearance of SKOV3 cells and ATCs. These results might suggest that exosomes did not contain the substances that could stimulate cancer cells to grow. The other explanation is that exosomes contained the substances that could effect the growth of cancer cells but the effect was not significant enough to be detected, or the target cells we used were insensitive to these substances.

We studied the effect of exosomes on the growth, apoptosis and morphology of cancer cells. It is still too early to say that exosomes did not have any effect on the cancer cells. We were not able to clarify whether exosomes affected the compositions and construction of cancer cells, or whether exosomes had an effect on the expression of some genes in cancer cells. Whether exosomes affect the cancer cells' ability of expression needs further study.

The in vitro anti-ovarian cancer cytotoxic activity of the PBMCs stimulated by ascites-derived exosomes. Both exosomes from DCs and tumor cells are considered to strengthen the host's anti-tumor immunological activity (2628). In addition, some studies reported exosomes could affect $\mathrm{T}$ cells only when DC existed $(29,30)$. Other studies reported exosomes could affect $\mathrm{T}$ cells directly without the assistance of DC $(31,32)$. Recently, studies reported that exosomes could not stimulate the ability of $\mathrm{T}$ cells to kill cancer cells but might induce the apoptosis of $\mathrm{T}$ cell $(10,33,34)$. So, it is not clear whether exosomes regulate the anti-ovarian cancer immunological activity directly or indirectly, and positively or negatively. In our study, we found whether PBMCs were from ovarian cancer patients or not, the target cells were SKOV3 cells or ATCs, the ability of PBMCs to kill cancer cells was always impaired when exosomes and DCs co-existed. But exosomes alone could not affect the ability of PBMCs to kill cancer cells. The results might suggest that on one hand exosomes could downregulate the host anti-tumor immunological function, and on 
the other hand, exosomes should have effect on PBMCs by the assistance of DC.

The results of our study were different from other studies which showed exosomes had the ability to strengthen the cytotoxic activity of $\mathrm{T}$ cell. The reasons might that: firstly, exosomes studied in most research were from pure DCs $(35,36)$ or tumor cell lines $(26,27,37,38)$. Exosomes from DCs have been identified to have the ability to activate immunological cells. Until now, there is no evidence that suggest exosomes from DC can down-regulate the activity of T cells. Some authors thought exosomes from cancer cells can activate $\mathrm{T}$ cells because of exosomes containing tumor antigens. However, it was reported that exosomes from human prostate cancer cell line LNCaP could induce apoptosis of $\mathrm{CD}^{+} \mathrm{T}$ cells by expressing FasL (34). In our study, the multi-origin of cells in ascites might attribute to the multi-origin of exosomes. The effect of exosomes on immunological cells might be influenced by two factors: 1) The cells produce more exosomes and 2) the cells produce the exosomes with more activity. Whether exosomes from tumor cell lines are different from that from tumor cells in vivo also needs further study. The procedure of our study was different from that of other studies. Our main reference was the study of Andre et al (9) that exosomes derived from malignant effusion could strengthen the cytotoxic activity of immunological cells when DC existed. But our study was different from that of Andre et al (9) in some aspects. In their study, $3 \times 10^{4}$ DCs were cultured with exosomes equivalent to $10 \mathrm{ml}$ malignant effusion or culture supernatant for $2 \mathrm{~h}$. Peripheral blood lymphocytes were then added at a ratio of three lymphocytes to one DC. They stimulated the peripheral blood lymphocytes in vitro once a week for a total of two or three stimulations. In our study, the ratio and the way of DCs stimulated by exosomes was the same, but we stimulated PBMCs for only 1 week. One reason was that PBMCs remained alive only for a week under the IL-2 concentration in our study. The other reason was that some PBMCs died significantly when cultured with exosomes and we did not manage to harvest enough cells. The shorter stimulation time might weaken the ability of DC to capture, treat and process the antigens expressed on exosomes, but it might not make DCs to impair the anti-tumor activity of $\mathrm{T}$ cells. A reasonable explanation is that exosomes might have the ability of two-way regulation, depressing immunological cells when stimulated for a short time or less cycle and activating immunological cells when stimulated for a long time and more cycles.

We found the level of IFN- $\gamma$ released by PBMCs which were stimulated by DCs plus exosomes was slightly less than PBMCs which were stimulated by DCs or exosomes alone. No more IFN- $\gamma$ was released by PBMCs when co-cultured with tumor cells, indicating the aspect of IFN- $\gamma$, exosomes could not activate PBMCs and might even weaken the ability of PBMCs to secret IFN- $\gamma$ when DCs exist. However, we needed to confirm our results on larger number of samples.

The mechanism of the effect of exosomes on DCs and PBMCs The effect on DCs. Among 3 independent tests, we found ascites-derived exosomes could induce apoptosis of precursor cells of DC in one test, which might be a way that exosomes down-regulated immunological function. Why exosomes could not induce apoptosis of all precursor cells of DC was not clear. The exosomes that induced apoptosis of precursor cells of DC were derived from a patient with stage IV poorly differentiated ovarian adenocarcinoma. The patient's CA125 was $>60000 \mathrm{IU} / \mathrm{ml}$. The other exosomes that could not induce apoptosis were derived from 2 patients with stage IIIC and poorly differentiated adenocarcinoma. Their CA125 was 177.0 IU/ml and 356.7 UI/ml, respectively. We presumed that with higher CA125 levels, the patients had more tumor cells and more exosomes produced by tumor cell. Unlike the exosomes from DC, the exosomes produced by tumor cells might induce apoptosis of precursor cells of DCs.

Similar to precursor cells of DC, 2 of the 3 independent tests DCs could be induced to apoptosis by ascites-derived exosomes. The exosomes which induced apoptosis were from a patient with phase IIc, poorly differentiated clear cell carcinoma combined with endometrioid carcinoma, and a patients with phase IIIc, poorly differentiated serous carcinoma combined with endometrioid carcinoma. The CA125 level of these patients was 556.5 and $1104.34 \mathrm{IU} / \mathrm{ml}$, respectively. So we presumed that exosomes from the patient with composite tumorous components might induce apoptosis more easily.

The effect on PBMCs. Exosomes might interact with PBMCs by affecting the number or the compositions of PBMCs. T cells that participate the anti-tumor cell immunity are $\mathrm{CD}^{+} /$ CD4 ${ }^{+} \mathrm{T}$ cells $\left(\mathrm{T}_{\mathrm{H}}\right.$ cell) and $\mathrm{CD} 3^{+} / \mathrm{CD}^{+} \mathrm{T}$ cells $\left(\mathrm{T}_{\mathrm{C}}\right.$ cell). In clinical practice, the cell immunity function can be evaluated by testing the ratio of $\mathrm{CD}^{+} / \mathrm{CD}^{+} \mathrm{T}$ cells and $\mathrm{CD}^{+} / \mathrm{CD}^{+} \mathrm{T}$ cells in a blood sample. If the cell immunity is normal, the ration is $>1$. In our study, we did not find that exosomes affected the ratio of $\mathrm{CD}^{+} / \mathrm{CD}^{+} \mathrm{T}$ cells and $\mathrm{CD}^{+} / \mathrm{CD}^{+} \mathrm{T}$ cells in PBMCs. Considering exosomes should affect $\mathrm{T}$ cells with the assistance of DC, we studied whether exosomes affected the ratio of $\mathrm{CD}^{+} / \mathrm{CD}^{+} \mathrm{T}$ cells and $\mathrm{CD}^{+} / \mathrm{CD}^{+} \mathrm{T}$ cells in the presence of DCs. However, the ratio did not change. So, we concluded that exosomes did not impact the anti-tumor immunological function by changing the ratio of $\mathrm{T}_{\mathrm{H}}$ cells and $\mathrm{T}_{\mathrm{C}}$ cells.

If the cytotoxic activity of $\mathrm{T}_{\mathrm{C}}$ is activated or impaired, its ability to attack the tumor cells will be changed. Our study showed exosomes could not influence the secreting IFN- $\gamma$ level of PBMCs, and exosomes could not influence the FasL expression of PBMCs either, which meant exosomes did not impact the anti-tumor immunological function by changing the membrane molecule expression of T cells.

Recently, some studies have improved exosomes derived from tumor cells $(34,39)$, the ascites of ovarian cancer patients (9) or the serum (11) of tumor patients can induce apoptosis of T cells. In our study, 2 in $5(40 \%)$ independent tests found exosome-induced apoptosis of PBMCs. When DCs existed, 3 in 6 (50\%) independent tests found exosome-induced apoptosis of PBMCs. The exosomes used in the tests were derived from 2 patients. One patient had phase IIIc, poorly differentiated serous ovarian carcinoma and her CA125 level was $1848 \mathrm{IU} / \mathrm{ml}$. The other patient had phase IV, poorly differentiated ovarian adenocarcinoma and her CA125 level was $487 \mathrm{IU} / \mathrm{ml}$. The PBMCs that induced 
apoptosis were harvested from both ovarian cancer patients blood and healthy volunteers' blood. Therefore, we concluded that the pathological type of tumor, the CA125 level and the origin of PBMCs could not predict whether exosomes could induce apoptosis of PBMCs. The different effects of exosomes on the apoptosis of PBMCs might be a reason of the different results of different studies.

The mechanism of apoptosis of immunological cells induced by exosomes. If exosome can induce apoptosis of PBMCs or DCs, it should activate the 'waterfall reaction' of apoptosis. One possibility is that exosomes contain apoptosis-induction signal molecules. FasL and TRAIL are the molecules that have been studied the most. FasL is the member of the tumor necrosis factor (TNF) family. If the target cell contains the receptor of FasL (Fas), the combination of Fas and FasL will induce apoptosis of the target cell. A study has shown there is Fas on the surface of T cells (40), which has an important significance on regulation of autoimmunity and interruption of over activation of $T$ cells. In our study, we found FasL in the suspension of exosomes and FasL located on surface of exosomes, which were similar to some studies $(34,41,42)$. When we used specific anti-FasL antibody to block the effect of exosomes on PBMCs and DCs, we found 1 in 3 independent tests the apoptosis level of PBMCs or DCs decreased to the level of PBMCs or DCs without exosomes. Based on the results above, we concluded that: 1), FasL on exosomes took part in the induction of apoptosis of PBMCs or DCs in some cases. But the expression levels of FasL in different exosome samples were different, and the difference in FasL levels might be a reason of the discordant effect on apoptosis of PBMCs or DCs. 2), The failure of blocking apoptosis of PBMCs or DCs by specific antibody in some tests might be due to insufficient amount of antibody. 3), Exosomes might induce apoptosis of PBMCs or DCs by other pathways besides Fas/FasL, which could not be blocked by anti-FasL antibody.

TRAIL, a new apoptosis induced signal molecule whose molecular weight is $32.5 \mathrm{kD}$, is also a member of TNF family (43). There are 4 receptors of TRAIL, DR4/DR5/DcR1/DcR2. The classic view is that DR4/DR5 which can transfer the apoptosis signal is expressed mainly on tumor cells and rarely on normal cells, and DcR1/DcR2 which are defective receptors to transfer apoptosis signal are expressed mostly on normal cells and with low expression on tumor cells. So TRAIL can just induce apoptosis on tumor cells but not on normal cells (43). Recent studies have shown TRAIL can induce apoptosis of $\mathrm{T}$ cells to regulate the activationinduced death (ACID) (44). Other studies also have proved exosomes from melanoma (39) or T cells (44) contain TRAIL. In our study membrane-combined TRAIL existed in the exosomes suspensions, but we were not sure whether these exosomes containing TRAIL were from ovarian cancer cells or activated T cells. Martínez-Lorenzo et al (39) reported that like FasL, tumor cells produce exosomes containing TRAIL to resist attack by the immunological system. We found there were low levels of DR4/DR5 expressed on DCs and PBMCs, so we hypothesized that on one side, ovarian cancer cells could induce apoptosis of activated $\mathrm{T}$ cells by secreting exosomes expressing TRAIL to escape the attack of immunological cells, and on the other side, activated T cells can secret exosomes expressing TRAIL to attack tumor cell and induced apoptosis of other T cells to avoid over-activation. However, we did not performed the blockade to TRAIL.

In conclusion, novel functional vesicles, exosomes, exist in ascites of $85.4 \%$ patients with ovarian cancer. These exosomes might be of multi-origin. Exosomes had no effect on the growth and apoptosis of tumor cells but impaired the cytotoxic activity of peripheral blood mononuclear cells in the presence of dendritic cells. Exosomes also might induce apoptosis of the precursor cells of dendritic cells, dendritic cells and peripheral blood mononuclear cells. FasL and TRAIL on exosomes might be partly the reason for apoptosis of immunological cells.

Exosomes may have a distinct role in the regulation of the tumor-anti tumor interaction. Exploring the function of exosomes can help to understand the malignant bio-behavior of tumor and the interaction between tumor and immune system. But we still have only slight knowledge on ascitesderived exosomes from ovarian cancer patients. The interaction between tumor and host immune system is so complex that further study must be perform to clarify the function of exosomes.

\section{References}

1. Keryer-Bibens C, Pioche-Durieu C, Villemant C, et al: Exosomes released by Epstein-Barr virus infected nasopharyngeal carcinoma cells convey the viral Latent Membrane Protein 1 and the immunomodulatory protein galectin 9. BMC Cancer 6: 283, 2006.

2. Savina A, Furlan M, Vidal M, et al: Exosome release is regulated by a calcium-dependent mechanism in K562 cells. J Biol Chem 278: 20083-20090, 2003.

3. Hegmans JP, Bard MP, Hemmes A, et al: Proteomic analysis of exosomes secreted by human mesothelioma cells. Am J Pathol 164: 1807-1815, 2004.

4. Navabi H, Croston D, Hobot J, et al: Preparation of human ovarian cancer ascites-derived exosomes for a clinical trial. Blood Cells Mol Dis 35: 149-152, 2005.

5. Segura E, Amigorena S and Thery C: Mature dendritic cells secrete exosomes with strong ability to induce antigen-specific effector immune responses. Blood Cells Mol Dis 35: 89-93, 2005.

6. Raposo G, Nijman HW, Stoorvogel W, et al: B lymphocytes secrete antigen-presenting vesicles. J Exp Med 183: 1161-1172, 2005.

7. Kapsogeorgou EK, Abu-Helu RF, Moutsopoulos HM, et al: Salivary gland epithelial cell exosomes: a source of autoantigenic ribonucleoproteins. Arthritis Rheum 52: 1517-1521, 2005.

8. Mallegol J, van Niel G and Heyman M: Phenotypic and functional characterization of intestinal epithelial exosomes. Blood Cells Mol Dis 35: 11-16, 2005.

9. Andre F, Schartz NE, Movassagh M, et al: Malignant effusions and immunogenic tumour-derived exosomes. Lancet 360 : 295-305, 2002 .

10. Taylor DD, Taylor GC, Lyons KS, et al: T-cell apoptosis and suppression of $\mathrm{T}$-cell receptor CD3-zeta by Fas ligand containing membrane vesicles shed from ovarian tumors. Clin Cancer Res 9: 5113-5119, 2003.

11. Taylor DD and Gercel-Taylor C: Tumour-derived exosomes and their role in cancer-associated T-cell signalling defects. Br J Cancer 92: 305-311, 2002.

12. Le Pecq JB: Dexosomes as a therapeutic cancer vaccine: from bench to bedside. Blood Cells Mol Dis 35: 129-135, 2005.

13. Johnstone RM, Bianchini A and Teng K: Reticulocyte maturation and exosome release: transferrin receptor containing exosomes shows multiple plasma membrane functions. Blood 74: 1844-1851, 1989 . 
14. Schartz NE, Chaput N, Andre F, et al: From the antigenpresenting cell to the antigen-presenting vesicle: the exosomes. Curr Opin Mol Ther 4: 372-381, 2002.

15. Bard MP, Hegmans JP, Hemmes A, et al: Proteomic analysis of exosomes isolated from human malignant pleural effusions. Am J Respir Cell Mol Biol 31: 114-121, 2004.

16. Denzer K, van Eijk M, Kleijmeer MJ, et al: Follicular dendritic cells carry MHC class II-expressing microvesicles at their surface. J Immunol 165: 1259-1265, 2000.

17. Clayton A, Court J, Navabi H, et al: Analysis of antigen presenting cell derived exosomes, based on immuno-magnetic isolation and flow cytometry. J Immunol Methods 247: 163-174, 2001 .

18. Chaput N, Flament C, Viaud S, et al: Dendritic cell derivedexosomes: biology and clinical implementations. J Leukoc Biol 80: 471-478, 2006.

19. Wieckowski E and Whiteside TL: Human tumor-rerived vs rendritic cell-derived exosomes have distinct biologic roles and molecular profiles. Immunol Res 36: 247-254, 2006.

20. Blanchard N, Lankar D, Faure F, et al: TCR activation of human $\mathrm{T}$ cells induces the production of exosomes bearing the TCR/CD3/zeta complex. J Immunol 168: 3235-3241, 2002.

21. Thery C, Zitvolgel L and Amigorena S: exosome: composition, biogenesis and function. Nat Rev Immunol 2: 569-579, 2002.

22. Rialland P, Lankar D, Raposo G, et al: BCR-bound antigen is targeted to exosomes in human follicular lymphoma Bcells. Biol Cell 98: 491-501, 2006.

23. Skokos D, Botros HG, Demeure C, et al: Mast cell-derived exosomes induce phenotypic and functional maturation of dendritic cells and elicit specific immune responses in vivo. J Immunol 170: 3037-3045, 2003.

24. Denzer K, Kleijmeer MJ, Heijnen HF, et al: Exosome: from internal vesicle of the multivesicular body to intercellular signaling device. J Cell Sci (113 Pt) 19: 3365-3374, 2000.

25. Mor-Vaknin N, Punturieri A and Sitwala K: The DEK nuclear autoantigen is a secreted chemotactic factor. Mol Cell Biol 26: 9484-9496, 2006.

26. Wolfers J, Lozier A, Raposo G, et al: Tumor-derived exosomes are a source of shared tumor rejection antigens for CTL crosspriming. Nat Med 7: 297-303, 2001.

27. Chen W, Wang J, Shao C, et al: Efficient induction of antitumor $\mathrm{T}$ cell immunity by exosomes derived from heat-shocked lymphoma cells. Eur J Immunol 36: 1598-1607, 2006.

28. Taieb J, Chaput N and Zitvogel L: Dendritic cell-derived exosomes as cell-free peptide-based vaccines. Crit Rev Immunol 25: 215-223, 2005.

29. Thery C, Duban L, Segura E, et al: Indirect activation of naive $\mathrm{CD} 4^{+} \mathrm{T}$ cells by dendritic cell-derived exosomes. Nat Immunol 3: 1156-1162, 2002.

30. Vincent-Schneider H, Stumptner-Cuvelette P, Lankar D, et al: Exosomes bearing HLA-DR1 molecules need dendritic cells to efficiently stimulate specific T cells. Int Immunol 14: 713-722, 2002.
31. Kovar M, Boyman O, Shen X, et al: Direct stimulation of T cells by membrane vesicles from antigen-presenting cells. Proc Natl Acad Sci 103: 11671-11676, 2006.

32. Sprent J: Direct stimulation of naive $\mathrm{T}$ cells by antigenpresenting cell vesicles. Blood Cells Mol Dis 35: 17-20, 2005.

33. Jeong WK, Eva W, Taylor DD, et al: Fas ligand-positive membranous vesicles isolated from sera of patients with oral cancer induce apoptosis of activated T lymphocytes. Clin Cancer Res 11: 1010-1020, 2005.

34. Abusamra AJ, Zhong Z, Zheng X, et al: Tumor exosomes expressing Fas ligand mediate CD8 ${ }^{+}$T-cell apoptosis. Blood Cells Mol Dis 35: 169-173, 2005.

35. Hao S, Bai O, Li F, et al: Mature dendritic cells pulsed with exosomes stimulate efficient cytotoxic T-lymphocyte responses and antitumour immunity. Immunology 120: 90-102, 2006.

36. Zitvogel L, Regnault A, Lozier A, et al: Eradication of established murine tumors using a novel cell-free vaccine: dendritic cell-derived exosomes. Nat Med 4: 594-600, 1998.

37. Dai S, Wan T, Wang B, et al: More efficient induction of HLA-A*0201-restricted and carcinoembryonic antigen (CEA)-specific CTL response by immunization with exosomes prepared from heat-stressed CEA-positive tumor cells. Clin Cancer Res 11: 7554-7563, 2005.

38. Yang Y, Xiu F, Cai Z, et al: Increased induction of antitumor response by exosomes derived from interleukin-2 gene-modified tumor cells. J Cancer Res Clin Oncol 30: 105-108, 2007.

39. María José ML, Alberto A, María AA, et al: The human melanoma cell line MelJuSo secretes bioactive FasL and APO2L-TRAIL on the surface of microvesicles. Possible contribution to tumor counterattack. Exp Cell Res 295: 315-329, 2004.

40. Zhang J, Xu X and Liu Y: Activation-induced cell death in T cells and autoimmunity. Cell Mol Immunol 1: 186-192, 2004.

41. Alonso R, Mazzeo C, Merida I, et al: A new role of diacylglycerol kinase alpha on the secretion of lethal exosomes bearing Fas ligand during activation-induced cell death of $\mathrm{T}$ lymphocytes. Biochimie 89: 213-221, 2006.

42. Alonso R, Rodriguez MC, Pindado J, et al: Diacylglycerol kinase alpha regulates the secretion of lethal exosomes bearing Fas ligand during activation-induced cell death of $\mathrm{T}$ lymphocytes. J Biol Chem 280: 28439-28450, 2005.

43. Rakesh K and Srivastava: TRAIL/APO-2L: mechanisms and clinical applications in cancer. Neoplasia 3: 535-546, 2001

44. Jeremias I, Herr I, Boehler T and Debatin KM: TRAIL/APO2ligand-induced apoptosis in human $\mathrm{T}$ cells. Eur J Immunol 28: 143-152, 1998. 